\title{
LAS DIPUTACIONES PROVINCIALES AMERICANAS EN EL SISTEMA LIBERAL ESPAÑOL
}

\author{
POR \\ ASCENSION MARTINEZ RIAZA
}

En el vasto plan de reformas que emprenden las Cortes de Cádiz con el propósito de desmantelar las bases sobre las que se sustentaba el absolutismo hay que encuadrar aquellas que pretenden crear instituciones representativas, bien remodelando algunas ya existentes (caso de los ayuntamientos constitucionales), bien proyectando otras de nuevo cuño. Entre estas últimas se encuentran las diputaciones provinciales.

Sus objetivos son ambiciosos por cuanto se orientan a modernizar y racionalizar el gobierno territorial de la Península y Ultramar, tanto en sus aspectos políticos como económicos. A medida que se suceden las legislaturas van ganando importancia y competencias y en ciertos momentos son centro de acalorados debates en el seno de la Cámara. Las discusiones alcanzan el cénit cuando atañen a la estructuración y funcionamiento de las diputaciones ultramarinas: número, prerrogativas, relación con otras instituciones... Mientras que la mayoría de los diputados peninsulares ven en su proliferación un riesgo patente de desunión, para los americanos se trata de un instrumento para controlar los excesos del poder y un medio eficaz para gestionar de una manera más directa sus propios asuntos.

En la representación americana en las Cortes serán los diputados mexicanos y centroamericanos quienes van a encauzar las propuestas y mantener una posición más reivindicativa. Destaca sin duda el novohispano Ramos Arispe, que participó en comisiones y dirigió los debates más acalorados. Por el contrario, la participación por el Perú, el otro gran virreinato, fue muy escasa, limitándose a dos representantes, Inca Yupanqui y Ribero.

Siglas UTILIZADAS:

BNP: Biblioteca Nacional del Perú, Lima.

CDO: Colección de Decretos y Ordenes que han expedido las Cortes (1810-1814).

DDC: Diario de las Discusiones y Actas de las Cortes (1811-1813).

DSC: Diario de Sesiones de las Cortes (1820-1823). 
En Ultramar, la trayectoria de las diputaciones provinciales estuvo condicionada por el proceso de insurgencia que se inicia hacia 1810. Así en el Río de la Plata la institución no llegó a funcionar ya que a partir de mayo de 1810 el territorio se comporta como independiente de hecho, sin embargo, en Cuba y Puerto Rico se mantuvo durante largo tiempo. En cuanto a los dos grandes centros del poder español, las diputaciones provinciales siguieron un proceso desigual. En Nueva España; la institución se desarrolló progresivamente ganando en número y competencias y llegando a ser pieza clave en la organización federal de la República. El caso del Perú es prácticamente desconocido, existieron desde luego las diputaciones, y por los datos con los que se cuenta puede deducirse que tuvieron un carácter marcadamente fidelista.

\section{NACIMIENTO Y ASCENSO DE UNA INSTITUCIÓN}

\subsection{Origen y debates iniciales. Primeras intervenciones americanas}

El origen inmediato de las diputaciones provinciales hay que buscarlo en las juntas provinciales que se forman a partir de 1808 en la España no ocupada por las tropas francesas. Sin embargo, existía toda una tradición de organización territorial gestada desde los tiempos de la presencia romana en que ya se introdujo la división provincial para facilitar la administración del Imperio. Más adelante, la ordenación visigótica recogería la técnica divisoria romana, e incluso los reinos de taifas que se generan en los restos de territorio que conserva el Islam serán módulos que se trasladarán en parte a las futuras provincias (1).

Durante la España moderna son jalones a tener en cuenta, para entender la evolución del sistema provincial, el Auto Acordado de Carlos II, la reorganización corregimental y de alcaldías mayores de Felipe $\mathrm{V}$ y las innovaciones introducidas por la Ordenanza de Intendentes y la Ley 22 de la Novísima Recopilación

(1) Eduardo Roca Roca, "Los orígenes constitucionales de la provincia" en Provincia y Diputación Provincial en el Estado de las Autononias. Centro de Estudios Municipales y de cooperación interprovincial de las Exmas. Diputaciones Provinciales de Almería, Granada y Jaén, págs. 16-18 (Granada 1982). 
de Carlos IV (2). Será el conde de Floridablanca el que, al asumir la presidencia de la Junta Central en 1809, trate de conciliar las Juntas y las provincias. Al pretender dar a las primeras estabilidad como organismos provinciales, da paso a la fórmula de la Diputación provincial tal y como iría quedando luego configurada (3).

Pero las Juntas se superponen a las capitanías generales e intendencias preexistentes con los consiguientes conflictos y desarreglos. Por ello, y dada la necesidad de contar con una organización que permitiera el funcionamiento de la administración y la recaudación de fondos, las Cortes de Cádiz tratan de tomar medidas para despejar la confusión. Las primeras iniciativas, de escasa eficacia, incluyen el nombramiento el 14 de octubre de 1810 de una comisión que elaborara un reglamento de administración provincial. Presentado exactamente un mes después, es rechazado el 20 de diciembre. La oposición fue general, los diputados no podían aceptar semejante descentralización provincial, ni la desconexión que contemplaba entre las Diputaciones y el gobierno central (4).

En la misma sesión se acuerda encargar a otra comisión un nuevo texto. Tras una presurosa lectura, que se inicia el 4 de marzo de 1811, es aprobado el día 18 bajo el título de Reglamento Provisional para el gobierno de las Juntas de Provincia (5). Supone un intento de conciliación entre un centralismo excesivo y una desmedida liberalización de la administración provincial. Atendiendo al número de partidos existentes en cada provincia se establecería una Junta superior compuesta al menos de nueve miembros, que se renovarían anualmente por tercios; el intendente sería miembro nato y estaría presidida por el capitán general. Sus funciones cubrían un amplio abanico: recaudación de caudales públicos, formación del censo, creación de centros de enseñanza, supervisión del alistamiento de tropas y cuidado

(2) Demetrio Ramos, "El origen de las provincias y su relación con la evolución de las Cortes" en La Provincia, dimensiones histórica y politica. Instituto de Ciencias Sociales, págs. 27-28. (Barcelona 1966.) En su opinión se valora excesivamente la división introducida por la Revolución Francesa y su aplicación por Napoleón en los territorios peninsulares que llegó a ocupar: por Decreto de 17 de abril de 1810 José I ordenó la división en 38 prefecturas y 111 distritos 0 subprefecturas.

(3) Ibidem, pág. 36.

(4) Manuel Martinez Sospedra, La Constitución de 1812 y el primer liberalismo español. Cátedra F. Furió Ceriol, págs. 138-140 (Valencia 1978).

(5) Colección de Decretos y Ordenes que han expedido las Cortes Generales y Extraordinarias desde su insialación de 24 de septiembre 1810 hasta el 11 de mayo 1814 (en adelante C.D.O. 1810-1814), Imprenta Nacional (Madrid, 1814), tomo l, págs. 90-103. 
de su abastecimiento, sanidad, etc. Tenía carácter provisional hasta la aprobación de la Constitución, pero contiene ya buena parte de las disposiciones relativas a la administración provincial que luego se perfilarían. Puede considerarse el eslabón entre las juntas provinciales y las Diputaciones.

El Reglamento concierne únicamente a los territorios peninsulares. Esta marginación molestó a los diputados americanos que desde el principio se sintieron en inferioridad y trataron de mejorar sus posiciones. Las Once Proposiciones presentadas el 16 de diciembre de 1810 sintetizan sus principales demandas (6).

La primera protesta registrada la realiza el diputado por Nueva Granada José Mejía Lequerica (suplente por Quito, oficial de la Secretaría de Gracia y Justicia). Prevalece la opinión de miembros relevantes de la comisión de Constitución, Agustín Argüelles y Evaristo Pérez de Castro entre ellos, que piden un compás de espera en las reivindicaciones hasta que se promulgue la Constitución. La tregua se rompe al incorporarse a las Cortes el diputado novohispano José Miguel Ramos Arizpe. El 1 de noviembre presenta una memoria, argumentando la necesidad de dotar a América de un reglamento provincial, en ella aparece ya la expresión Diputación provincial (7).

A comienzos de octubre se había inciado en el seno de la comisión de Constitución la elaboración de los dos capítulos del

(6) Con sobrados motivos los americanos se sentían relegados. Para comenzar su número siempre fue inferior al de los peninsulares. En cualquier caso no hay coincidencia entre los investigadores a la hora de precisar el número de diputados americanos presentes en las Cortes: la precipitación en las convocatorias, las suplencias e incorporaciones escalonadas de los propietarios y el no estar siempre firmadas las Actas por todos ellos dificulta las valoraciones. Según Demetrio RAMOS, en el acto de apertura en la Isla de León estaban presentes 27 diputaos americanos, ver su artículo "Las Cortes de Cádiz y América" Revista de Estudios Políticos $\mathrm{n}^{2}$ 126, pág. 472 (Madrid, 1962). Dos trabajos recientes permiten un mejor conocimiento de los diputados americanos tanto en lo relacionado con su adscripción socioprofesional y geográfica como a sus intereses y actividad en las Cortes. Teresa BERruezo, la participación americana en las Cortes de Cádiz, Instituto de Estudios Políticos (Madrid, 1986) y Marie-Laure RIEU-MILLAN, Los diputados americanos en las Cortes de Cádiz. Madrid. Centro de Estudios Históricos. CSIC, 1990.

(7) El papel de Ramos Arizpe (o Arispe) en las Cortes, y más concretamente su actuación en relación a la Diputación provincial es analizado en el mejor trabajo que conocemos sobre la institución en América. Se trata de la obra de Nettie Lee BENSON, La Diputación Provincial y el federalismo mexicano. (México, 1955.) Se basa en los Diarios de Sesiones de las Cortes hasta la sesión del 20 de abril de 1812, a partir de entonces sus referencias remiten a las Colecciones de Decretos y Ordenes. Se centra exclusivamente en las intervenciones de los diputados mexicanos y centroamericanos y en la proyección de la institución en México. Su tesis es que las diputaciones provinciales creadas por las Cortes fueron la base del sistema sistema federal mexicano postindependentista.

\section{R. I., 1992, nos 195/196}


Título VI del proyecto de Constitución referentes a Ayuntamientos y Diputaciones provinciales. El día 11 se permite que los miembros americanos hagan por separado sus propuestas para ser luego analizadas conjuntamente, afloran ya discrepancias que luego provocarán duros enfrentamientos en la Cámara entre peninsulares y americanos. Las sesiones de las Cortes en que se discute el citado Título VI del Proyecto, especialmente las que se celebran entre el 12 de enero y el 27 de febrero de 1812, reflejan la complejidad, y por qué no decirlo, la ambigüedad de la problemática. Para seguir los puntos más significativos nos centraremos en las referencias a Ultramar y en las intervenciones de los diputados americanos (8).

La organización jerárquica del poder en las Diputaciones, su composición, el alcance de sus competencias y su funcionamiento interno son los ejes en torno a los que gira el debate. Los americanos aprovechan para denunciar las fugas y vacíos de la administración ultramarina y, conscientes del peso que va a tener la nueva institución, se valen de todas las ocasiones para demostrar la necesidad de que se establezca en aquellos territorios el número justo en función de su riqueza y población.

Joaquín Fernández de Leyva, suplente por Chile, muestra su suspicacia en la sesión del 12 de enero en que se discute el artículo 322 del Proyecto que coloca al frente del gobierno político de las provincias a un jefe superior de designación real. Para evitar extralimitaciones sugiere que le acompañen dos adjuntos nombrados por la Diputación. Refuerza su argumento recordando que desde el inicio de la guerra contra Napoleón las provincias se gobernaron por autoridades colectivas que ellas mismas elegían. Su moción no llegaría a prosperar (9).

Tampoco están de acuerdo los americanos con la composición de miembros de la Diputación que ofrece la comisión (presidente, intendente y siete individuos más). En su nombre Antonio de Larrazábal, diputado por la ciudad de Guatemala, expresa la necesidad de aumentar el número en conformidad con la extensión y distancias existentes en América, siempre teniendo en cuenta que,

(8) Para la significación de las diputaciones en la Península, en relación con otras instituciones de la administración local ver Concepción de CASTRO, L.a Revolución Liberal y los municipios españoles. Madrid, Alianza Universidad, 1979.

(9) Diario de las Discusiones y Actas de las Cortes 1811-1813. Imprenta Real, Cádiz. 1811-1813, tomo XI, págs. 236-237. Sesión de 12 de enero de 1812. 
... es muy debido que las diputaciones instituidas en las capitales se compongan de sujetos de todas las provincias (hablo según lo que entendemos en América por provincias) (10).

Ramos Arizpe le apoya con energía, propugnando que su número esté en relación efectivamente con las dimensiones de la provincia y que en ningún caso sus miembros lo sean a perpetuidad, ni dependan directamente del gobierno. Abunda en la misma línea Andrés de Jáuregui, La Habana, puntualizando que en Ultramar el número debería bascular entre un máximo de trece y un mínimo de siete.

En esta sesión los peninsulares sacan ya a relucir el fantasma del federalismo. El conde de Toreno defiende que las Diputaciones sean agentes del poder ejecutivo y no cuerpos representativos; de lo contrario podría llegarse, sobre todo en Ultramar, a la gestación de una federación semejante a la de los Estados Unidos. Agustín Argüelles más moderado recuerda que la Diputación es entendida por la comisión,

como un ayuntamiento céntrico para reunir en un punto a todos los de las provincias y conservar la unión, haciendo en esto las mismas funciones que antes los acuerdos de las audiencias (11).

Los americanos responden: Fernández de Leyva desecha los temores puntualizando que los diputados provinciales son ante todo brazos auxiliares del gobierno supremo sin los poderes y facultades de los diputados del Congreso. Las posiciones se perfilan, para unos las diputaciones han de entenderse como cuerpos administrativos dependientes del gobierno, para otros han de ser cuerpos políticos representantes de la población y destinados a ser órganos de autogobierno.

Es un diputado americano. Florencio Castillo (por Costa Rica) el que pone el dedo en la llaga al profundizar hasta la raíz del problema que sistemáticamente se ha venido soslayando. No tiene sentido discutir sobre una realidad que no está definida y que es interpretada de diferentes maneras,

porque está sancionado que en cada provincia habrá una diputación provincial; pero no se ha expresado si éstas habrán de

(10) Ibidem, págs. 238-239.

(11) Ibidem, págs. 245-246. 
tomarse en el sentido que hasta aquí o si se han de tomar en mayor, llamando provincia lo que hasta aquí se ha llamado reyno (12).

La jornada del 14 de enero es especialmente rica en opiniones. De nuevo afloran las discrepancias de los diputados americanos al tratarse de los requisitos que han de reunir los miembros de la diputación (art. 328), el número de sesiones anuales que han de celebrarse (art. 332), el procedimiento para destituir a un diputado, y en fin algunas funciones concretas de la institución. En cuanto a la primera cuestión, Ramos Arizpe no se muestra partidario de aplicar a rajatabla el criterio de un mínimo de ingresos dada la dificultad de encontrar individuos que los tengan: tanto más cuanto la carrera más apropiada para los diputados es la de letrado y éstos a menudo carecen de bienes raíces. Larrazábal, por el contrario, sí lo considera imprescindible, siempre que esos ingresos no provengan de la industria o comercio (quienes practican esas actividades son con frecuencia transeúntes). La comisión acepta redactar una formulación general, que los diputados «tengan lo suficiente para mantenerse».

Cuando se llega a la precisión del número de sesiones (la comisión establece 90 días), Ramos Arizpe y Castillo cierran filas y piden un mínimo de seis meses dada la naturaleza de los temas a tratar. Muñoz Torrero les recuerda la posibilidad de establecer comisiones de dos o tres individuos en caso necesario (13).

La comisión sí acepta la modificación sugerida por el diputado por Cataluña señor Creus para que, en el caso especial de América, los jefes políticos tengan autoridad para suspender en sus funciones a los diputados que infrinjan la ley (prerrogativa real).

Dada la complejidad y extensión del artículo 333, que atiende a las diversas funciones de la diputación, se decide comentar y aprobar los puntos por separado. Dos de ellos tienen relación directa con Ultramar: el párrafo cuarto, que trata de la financiación de obras públicas y especifica que si la urgencia no permitiera esperar la resolución de las Cortes, podrá la diputación, con el visto bueno del jefe de la provincia, utilizar los arbitrios nece-

(12) Ibidem, 258. Sesión del 13 de enero 1812.

(13) Ibídem, 266-271. Más adelante, con fecha de 29 de noviembre de 1813, se publicará una orden para que, concluidas las 90 sesiones, se reúnan los miembros de la diputación en el segundo año sin pérdida de tiempo con el objetivo de ocuparse prioritariamente de intervenir en el adelanto del tercio de la contribución directa. Ver C.D.O. 1810-1813, V, 84. 
sarios dando cuenta al gobierno para la aprobación en el Congreso; y el párrafo noveno sobre la actitud hacia el indio:

las diputaciones de las provincias de Ultramar velarán sobre la economía, orden y progreso para la conversión de los indios infieles, cuyos encargados les darán razón de sus operaciones en este ramo para que se eviten los abusos, todo lo que las diputaciones pondrán en noticia del gobierno (14).

Los artículos del Proyecto que se refieren a la organización interna de las diputaciones, el procedimiento de renovación de los miembros (dos cada año, sale la primera vez el mayor número y la segunda el menor), el momento de la elección tanto de titulares como de suplentes, la no reelección consecutiva y el juramento que han de prestar de guardar la Constitución y cumplir sus deberes que se ven en esta jornada, son aprobados sin discusión (15).

El día 15 es de mero trámite, se pasan sucesivamente los artículos que restan para completar el capítulo II del título VI, que queda así visto para sentencia (16).

Durante los días siguientes las Cortes siguen ocupadas en la elaboración del texto constitucional. Pero la cuestión del gobierno y administración territoriales importa lo suficiente como para que, el 10 de febrero, la comisión de Constitución presente a la Cámara dos proyectos de decreto con vistas a su inmediata discusión y resolución. El primero dispone que en el interim se divide definitivamente el territorio se establezcan una serie de diputaciones provinciales en la Península e islas adyacentes (se enumeran), mientras en Ultramar se generaliza que las habrá en "cada una de las provincias que se nombran en el art. 11». El segundo atañe al papel de la diputación en la formación de ayuntamientos: cualquier pueblo que por sus particulares circunstancias considere que debe tener ayuntamiento, deberá ha-

(14) D.C.C. 1811-1813, XI, 273.

(15) Son respectivamente los artículos 330, 331, 325, 326, 327, 329 y 335 del Proyecto de Constitución.

(16) Son el requisito de que todos los años al instalarse la diputación provincial, el jefe político presente un manifiesto del estado político del "reyno" o "provincia" y "con respecto a Ultramar de las causas peculiares de colonización", y la formación de un consejo asesor que ha de ser aprobado por la diputación. 
cerlo presente a la diputación provincial para que ésta lo gestione (17).

En la sesión de 22 de febrero se informa que se han remitido 300 ejemplares a repartir entre los diputados y se señala el día siguiente para el debate. El choque entre varios diputados que se oponen a que se agreguen unas provincias a otras para constituir una nueva diputación provincial, y la comisión que justifica las modificaciones en función de poder dar a Ultramar un status de igualdad con la Península, es aprovechado por los diputados americanos para volver a la carga. El diputado Castillo reivindica la recta aplicación de la ley, si en América sólo se constituye una diputación en cada reino, la vida de tan benéfica institución se presenta mutilada desde el principio. Hay que aplicar un criterio de división que tenga en cuenta las desproporcionadas extensiones y distancias de aquellos territorios. Remite a sus intereses particulares poniendo como ejemplo el caso centroamericano: Guatemala exige al menos otra diputación en Nicaragua que se formaría agregándosele Comayagua y Costa Rica. El diputado Gordoa (por Zacatecas) no pierde la ocasión y aduce las mismas razones de extensión para pedir otra diputación para su demarcación (18).

\subsection{Las diputaciones provinciales en el marco de la Constitución de 1812}

Por lo que a la diputación provincial se refiere, la Constitución promulgada el 19 de marzo de 1812 es, a la vez, culminación de un largo proceso de discusión y punto de arranque de una serie de disposiciones que irán perfilando su significado y desarrollando sus competencias.

El título II «Del territorio de las Españas, su religión y gobierno y de los ciudadanos españoles» y el VI «Del gobierno interior de las provincias y de los pueblos» se ocupan en extenso de la organización provincial.

En el capítulo primero del título II, «Del territorio de las Españas", el artículo 10 especifica la división de reinos y provincias del espacio español en ese momento, siendo la primera vez

(17) D.C.C. $1811-1813$, XII, 4-5.

(18) Ibidem, 98-100 y 107. Sesiones de 23 y 25 de febrero de 1812. 
que encontramos tal división en un texto fundamental (19). Mientras, el artículo 11 advierte de la provisionalidad de esa división y anuncia una próxima estructuración mediante una nueva ley constitucional.

Pero son los dos capítulos que integran el título VI los que se dedican intensivamente a los ayuntamientos, gobierno político de las provincias y diputaciones provinciales. Encontramos ya planteada en el articulado una potencial interferencia de competencias entre ayuntamientos y diputaciones que cristalizará al extenderse en leyes sucesivas las prerrogativas de las últimas el caso del Perú es un ejemplo palpable.

Cuando se señalan las funciones de los ayuntamientos se inmiscuye ya a las diputaciones, pues a ellas deben ser remitidas las ordenanzas municipales para que a su vez las presenten a las Cortes (20). En última instancia, los ayuntamientos son entendidos como cuerpos administrativos que han de cumplir lo cometido bajo la inspección de la diputación provincial, a la que darán cuenta al final de cada año, del uso que han hecho de los recursos con los que han contado (21).

El capítulo segundo precisa en extenso todo lo relativo a la composición, funcionamiento y atribuciones de las diputaciones provinciales. Lo más significativo de su proyección americana ha sido ya comentado al seguir el debate del Proyecto de Constitución. Sin embargo, quedan pendientes cuestiones tan candentes como el número de diputaciones a establecer y los criterios que se seguirán para hacerlo (22).

Pero no son los únicos títulos que hacen referencia a las diputaciones. A lo largo de todo el texto encontramos a la institución, que está presente en los más variados aspectos de la vida

(19) Sobre el espacio americano el texto reza: "En la América septentrional, Nueva España con la Nueva Galicia y península de Yucatán, Guatemala, Provincias Internas de Oriente, Provincias Internas de Occidente, isla de Cuba con las dos Floridas, la parte española de la isla de Santo Domingo, y la isla de Puerto Rico con las demás adyacentes a éstas y al continente en uno y otro mar. En la América meridional, la Nueva Granada, Venezuela, el Perú, Chile, provincias del Río de la Plata y todas las islas adyacentes en el mar Pacífico y en el Atlántico. En el Asia, las islas Filipinas y las que dependen de su gobierno".

(20) Artículo 321 (estará a cargo de los ayuntamientos) "... formar las ordenanzas municipales del pueblo y presentarlas a las Cortes para su aprobación por medio de la diputación provincial que las acompañará con su informe".

(21) Artículo 323 "Los ayuntamientos desempeñarán todos estos encargos bajo la inspección de la diputación provincial, a quien rendirán cuenta justificada cada año de los caudales públicos que hayan recaudado e invertido".

(22) Corresponde a los artículos 324-337 del título V, capítulo II de la Constitución. A lo largo del trabajo se irá siguiendo su desarrollo posterior. 
constitucional española. Así el título III "De las Cortes», establece como base para el número de diputados a Cortes la población de las provincias (23); fija el sistema de elección a través de juntas de parroquia de partido y por último de provincias, y dispone que a cargo de las provincias corran las dietas de los diputados que serán establecidas por las Cortes, puntualizándose que a los de Ultramar se les abonará además lo que precisen para gastos de desplazamiento (24). En el ámbito de la administración de justicia - título $\mathrm{V}$ "De los Tribunales y de la administración de Justicia en lo civil y criminal»- se hace depender el número de audiencias de la división territorial en provincias (25).

También el título VII "De las Contribuciones», confiere un importante papel a las provincias en la fijación y recaudación de tributos (26). De igual manera (título VIII «De la fuerza militar nacional») participan en la defensa de la nación al serles asignada una milicia compuesta por habitantes de cada una de ellas y que se regirá por una ordenanza particular (27).

En lo esencial, la Constitución da a las diputaciones un carácter político-administrativo, pero no representativo. Y, a pesar de la preeminencia que concede a las corporaciones locales, mantiene fuerte el principio centralizador, de sujección al ejecutivo a través de dos mecanismos: la subordinación a las Cortes y al jefe superior (28). No expresan la voluntad de sus electores, los mismos que designan a los diputados a Cortes, sino la del Rey con quien colaboran en la ejecución de las leyes en el ámbito local (29).

(23) Capítulo I, artículo 32. Ramos acentúa la preocupación de las Cortes por la formalización de las provincias como un medio de fijar el funcionamiento del cuerpo legislativo sobre la base de la representación proporcional. Ver artículo citado en nota [2], pág. 29.

(24) Capítulo V "De las juntas electorales de provincia". Artículos 78-103.

(25) Capítulo I, artículo 272 "Cuando llegue el caso de hacerse la conveniente división del territorio español indicada en el artículo 11, se determinará con respecto a ella el número de audiencias que han de establecerse y se les señalará territorio".

(26) Artículo 334 "Fijada la cuota de contribución directa, las Cortes aprobarán el repartimiento de ella entre las provincias, a cada una de las cuales se asignará el cupo correspondiente a su riqueza..." y artículo 346 "Habrá en cada provincia una tesorería, en la que entrarán todos los caudales que en ella se recauden para el erario público..."

(27) Es el capítulo II "De las milicias nacionales" artículos 362-363.

(28) Martínez SoSPEDRa [4], págs. 296-297. Opina que su objetivo fundamental era lograr un equilibrio entre la autoridad real necesaria y la libertad de los pueblos.

(29) Miguel Artola, "La España de Fernando VII" en Historia de España de Ramón Menéndez. Pidal. t. XXXII, Espasa Calpe, pág. 480 (Madrid, 1978). 


\section{LAS DIPUTACIONES PROVINCIALES DESDE LA CONSTITUCIÓN HASTA LA VUELTA AL ABSOLUTISMO}

En lo que afecta al gobierno económico y político de las provincias, la Constitución supone un marco legal que se amplía con posterioridad mediante una sucesión de instrucciones, reglamentos y órdenes. En medio de la vorágine documental, tres textos destacan por tratar los principales problemas que atañen a las diputaciones provinciales americanas. Dos de ellos se ven en las Cortes simultáneamente y se hacen públicos en la misma fecha, el 23 de mayo de 1812. Se trata respectivamente de la Instrucción conforme a la cual deberán celebrarse en las Provincias de Ultramar las elecciones a Cortes para las ordinarias del próximo año de 1813 y el Decreto de Establecimiento de las Diputaciones provinciales en la Península y Ultramar (30). Y dos son las cuestiones planteadas en los textos que van a suscitar discrepancias y provocar calurosas intervenciones de los diputados americanos: por una parte el sistema de financiación elegido para proveer las dietas y gastos de desplazamiento de los representantes ultramarinos; por otra, el número de diputaciones provinciales que es justo y conveniente se establezcan en aquellos territorios.

El tercero es la Instrucción para el gobierno económico y político de las provincias, promulgada el 23 de junio de 1813 y que supone la culminación de diversas tentativas de ajustar la administración provincial, delimitando las competencias y obligaciones de los tres ejes que la conforman: ayuntamientos, jefes políticos y diputaciones (31).

No son documentos independientes y autosuficientes, para comprender su significado es preciso conocer el entramado legislativo en que se insertan y acercarse, a través de los debates en las Cortes, a la toma de posiciones de los diputados americanos en torno a aquellos puntos que les afectan directamente.

Dada la complejidad de la problemática, con carácter operativo para un análisis comprensivo de la institución en lo que a su proyección americana se refiere, se ha optado por seguir un criterio temático desechando el meramente cronológico más asequible pero menos clarificador.

(30) Reproducido en C.D.O. 1810-1814, II, 217-220 y 224-226.

(31) Ibídem, IV, 112-135. 


\subsection{Establecimiento, número y financiación}

La Instrucción conforme a la cual deberán celebrarse en las Provincias de Ultramar las elecciones de Diputados de Cortes tiene carácter provisional y urgente, y pretende resolver un problema inmediato en tanto se organizan las diputaciones provinciales. Su interés estriba en que aborda ya la cuestión de la financiación de los representantes americanos, que se mantendrá básicamente en los términos que aquí se establecen. Dispone que en tanto entren en funcionamiento dichas diputaciones, una Junta preparatoria se encargará del seguimiento del proceso de elección de diputados a Cortes. Serán en su momento las diputaciones provinciales las que se encarguen de proporcionar los arbitrios necesarios para cubrir los gastos, proponiéndolos a su tiempo para la aprobación de las Cortes. Señala la cantidad de ciento diez reales diarios como dieta para todos los diputados pudiendo las juntas preparatorias recurrir para que se hagan efectivos los abonos a los fondos de la Hacienda pública en calidad de reintegro que deberán hacer las diputaciones provinciales. En el caso específico de los diputados de Ultramar

Se les asistirá por sus respectivas provincias con la decente asignación que proporcionalmente a la distancia se estime necesaria a juicio de las diputaciones provinciales para los gastos de ida y vuelta. (32).

Posteriormente, las Cortes arbitrarán medidas para facilitar la provisión de fondos declarando libres de derechos los caudales procedentes de Ultramar para sufragar las dietas (33). En general se pide a las diputaciones que consideren prioritarios los pagos de esas dietas a cargo de los fondos públicos (34).

Los debates alcanzan las más altas cotas cuando se centran en la discusión del Decreto de Establecimiento de las Diputaciones Provinciales en la Península y Ultramar que se inicia a finales del mes de abril de 1812. Las intervenciones de los diputados americanos son frecuentes y apuntan hacia el mismo objetivo: conseguir el aumento del número de diputaciones que corresponden a

(32) D.C.C. 1811-1813, XIII, 124-125. Sesión del 27 de abril de 1812. La cuestión especifica de la financiación se trata en los artículos XIII al XVII del texto definitivo.

(33) Por Orden de 30 de abril de 1814, en C.D.O. 1810-1814, V, 200-201.

(34) Orden de 9 de mayo de 1814, Ibidem, V, 107. El 15 de abril de 1814 una nueva disposición insta al rápido abono de las dietas y especifica las irresponsabilidades en que incurren las diputaciones que se demoran en hacerlo. Ibidem, 181. 
Ultramar. A partir de ahí, lógicamente, cada representante atiende a los intereses de su región. Para empezar rechazan mayoritariamente la propuesta que había presentado el día 20 la comisión de Constitución en el sentido de que, atendiendo a las consideraciones de «algunos diputados de Ultramar sobre el riesgo que supondría multiplicarlas allí en exceso", se mantuvieran aquellas "que expresamente se nombran en el artículo 10».

Florencio Castillo, diputado por Cartago (Costa Rica), abre el fuego pidiendo que, además de en Guatemala, haya otra diputación en Nicaragua, agregándosele las provincias de Honduras y Costa Rica (35). Le refrenda Larrazábal que añade una denuncia explícita: «es una monstruosa desigualdad atender a las provincias de Ultramar con una tercera parte de las diputaciones que se conceden en la Península", pide en consecuencia que se cree la de Nicaragua y además otra en Zacatecas, demanda a la que se suma el señor Gordoa y Barrios, diputado precisamente por esa provincia. O'Gavan por su parte, aprovecha para volver a reclamar la de Santiago de Cuba y, también en el ámbito del Caribe, Rus (por la Capitanía general de Caracas) cree conveniente la instalación de una diputación en Maracaibo, sobre todo ahora que Caracas se encuentra en poder de los insurgentes. El panorama de reivindicaciones se completa con la de Lisperguer (suplente por Buenos Aires) que considera insuficiente la existencia de una sola diputación (Buenos Aires) en el Río de la Plata, olvidando la importancia de Charcas y Potosí.

Por primera vez se manifiesta al respecto un diputado peruano, Dionisio Inca Yupanqui, que ya había participado en la sesión del día 21 pidiendo que se perfilaran las funciones de las diputaciones en Ultramar, sobre todo en lo relativo a repartimientos, ventas, enajenaciones y composiciones de tierras (36). Su inter-

(35) El análisis de las diputaciones centroamericanas ha sido abordado por Carmelo SÁENz DE SANTAMARÍA en "El proceso ideológico-institucional desde la Capitanía General de Guatemala hasta las Provincias Unidas del Centro de América: de provincias a estados" Revista de Indias nos. 151-152, págs. 219-285 (Madrid, 1978). Demuestra el papel decisivo de las diputaciones en el tránsito a la Independencia. En la Capitanía General de Guatemala, las provincias perdieron pronto su carácter puramente administrativo y fueron la base de los Estados federales.

(36) Dionisio Inca Yupanqui fue uno de los peruanos que más destacaron por sus intervenciones. Perteneciente a la familia imperial de los incas, se forma intelectualmente en la Península. Diputado a Cortes desde el 20 de septiembre de 1810, formando parte de distintas comisiones: forma de publicar en América el decreto de instalación de las Cortes, Marina y Guerra. Participa en diferentes discusiones, preocupándole especialmente la situación del indio americano. Favorable a las diputaciones provinciales insiste, sin embargo, en la posición fuerte de las Cortes. Para una caracterización más completa, ver BERRuEzo [6], págs. 124. 126. 
vención se inscribe en el marco general de las reclamaciones de los diputados que le antecedieron en la palabra. Aboga por el incremento de las diputaciones en el Virreinato del Perú de dimensiones desproporcionadas como para contar únicamente con una,

¡cómo es posible que desde Lima, que se halla situada en una extremidad del virreinato, a las orillas del mar, se consulte con la proxilidad que conviene la localidad, circunstancias y proporciones de cada provincia para aplicar con imparcial conocimiento las medidas y remedios adaptables a las necesidades de cada una!

La alternativa es hacer una división más racional de un territorio de más de quinientas leguas norte-sur. Pide en consecuencia,

que en el Perú se establezca en cada capital de intendencia una diputación provincial, y otra en el gobierno de Guayaquil, porque de este modo podrán lograrse las miras benéficas de V.M. y seremos consecuentes (37).

Yupanqui es, pues, partidario de hacer coincidir las diputaciones provinciales con las intendencias, evitando así la proliferación y superposición de demarcaciones y la conflictividad que de ello se deriva.

En el curso de las intervenciones, sólo Jáuregui entre los americanos, aconseja prudencia y esperar, antes de tomar decisiones, a contar con la información necesaria sobre el territorio su población y situación económica.

Argüelles tiene en cuenta este argumento cuando, refiriéndose explícitamente a Ultramar, recuerda las dificultades adicionales que añaden la complejidad de su división y administración, "se conocen provincias baxo el nombre de virreinatos y capitanías generales; pero la estadística no permite en el día otra división más exacta para establecer diputaciones cual se pretende». Es por eso que con buen tino la comisión promueve que, de momento, se limiten las diputaciones

(37) D.C.C. 1811-1813, XIII, 134-135. Sesión de 27 de abril de 1812 para seguir las distintas intervenciones. 
a las capitales de capitanías generales o a virreinatos, con arreglo a la Constitución, y déxense las demás para tiempo oportuno, que si se quiere será el de las Cortes futuras.

Los americanos Mendiola (por Querétaro) y Mexía (por Santa $\mathrm{Fe}$ ) se pronuncian igualmente por la vía moderada. El segundo incluso llega a considerar que en la situación presente lo más conveniente sería que en Ultramar no hubiera más que dos, una en la América meridional y otra en la septentrional. Un cambio de actitud notable, dado que fue él quien inició en diciembre de 1810 la batalla por un establecimiento justo de diputaciones en aquellos territorios.

Finalmente las Cortes, ante el cariz que va tomando el debate, aceptan la moción del conde de Toreno de que se reúnan los diputados americanos y presenten una propuesta conjunta. La discusión sobre el número de diputaciones en la Península no se iniciará hasta que la cuestión americana no se haya resuelto (38).

Conforme a esta resolución, los señores Larrazábal y Feliú, en nombre de los americanos, dan a conocer su dictamen el día 1 de mayo. Replegando velas, anteponen lo absolutamente necesario a lo que entienden es lo útil y justo y por ello acuerdan que

Se aumenten por ahora tres diputaciones; a saber: en el Perú, la del Cuzco; en Buenos Aires, la de Charcas; y en Nueva Granada, la de Quito. Y en la septentrional otras tres, a saber: en Nueva España, una en San Luis de Potosí, a la que se agregue Guanajuato; en Guatemala otra, que se fixará en León de Nicaragua con la provincia de Costa Rica; y en la isla de Cuba, otra en Santiago de Cuba (39).

En el mismo Decreto sobre el establecimiento de diputaciones provinciales en Ultramar se contempla el sistema de elecciones de los individuos que han de componer la diputación.

(38) Ibídem, 143-148. Sesión de 28 de abril de 1812.

(39) En el decreto de 23 de mayo de 1812 se recoge íntegramente la propuesta. El artículo 1 queda redactado en los siguientes términos: "Y en Ultramar las habrá en cada una de las que expresamente se nombran en el artículo 10, y además en el Perú la de Cuzco; en Buenos Aires la de Charcas; en la Nueva Granada la de Quito; en Nueva España la de San Luis de Potosí; en Goatemala la de León de Nicaragua; en la Isla de Cuba la de Santiago de Cuba". Ver C.D.O. 1810-1814, II, 224-225. 


\title{
2.2. Atribuciones y competencias
}

Las atribuciones que la Constitución da a las diputaciones se desarrollan y diversifican con el tiempo, llegando a cubrir un amplio abanico temático. Van a tener a su cargo el proveer de dietas y hacer frente a los gastos de viaje de los diputados a Cortes por las provincias, se ocupan de la financiación de las milicias provinciales y ejércitos nacionales, atienden a la fijación de contribuciones de guerra, sufragan los gastos de las Juntas de censura provinciales $\mathrm{y}$, sobre todo, supervisan el uso que hacen los ayuntamientos de los caudales de propios y arbitrios y participan en la fijación y recaudación de impuestos.

En cuanto a la provisión y control de recursos de los ejércitos, el artículo 32 del Reglamento para verificar la contribución extraordinaria de guerra impuesta por decreto de $1^{\circ}$ de abril de 1811 dispone que cada tres meses los intendentes habrían de pasar a la Junta de provincia, mientras existiera o a la diputación provincial, un estado de la suma total que en cada pueblo haya correspondido a los contribuyentes y las cantidades que han salido o entrado en las Tesorerías (40).

En la organización de un sistema más eficaz para recaudar fondos para el erario, las Cortes hacen participar a las diputaciones. El decreto sobre el Nuevo Plan de Contribuciones Públicas de 13 de septiembre de 1813 especifica en el artículo XV que,

\begin{abstract}
A las diputaciones provinciales toca intervenir y aprobar el repartimiento que se ha de hacer entre los pueblos de las contribuciones que cupieran a la provincia conforme a lo dispuesto en el artículo 335 de la Constitución.
\end{abstract}

Se acompaña una Instrucción para las Diputaciones provinciales dirigida a uniformar y facilitar la ejecución del anterior decreto, que además establece una contribución directa sobre la

(40) D.C.C. 1811-1813, XV, 50. Se discute y aprueba en la sesión de 25 de agosto de 1812. También aquí habría que situar la propuesta que el 14 de abril de 1814 hace el diputado por Baleares Moragues para que los presupuestos destinados a mantener al ejército se repartan entre las provincias y se hagan cargo de ellos las diputaciones valiéndose, si lo creen conveniente, de los ayuntamientos. Ibidem, XVIII, 332-333. 
riqueza territorial, industrial y comercial, en lugar de las rentas provinciales y estancadas que quedan extinguidas (41).

Compete además a las diputaciones, tras recoger la información necesaria sobre los recursos de sus demarcaciones, hacer el repartimiento ajustado sumando los productos de los tres ramos -agricultura, industria y comercio- cargando el tanto por ciento que se necesite para llenar el cupo asignado por las Cortes a cada provincia. Una vez cumplidos estos requisitos remitirán a los ayuntamientos notificación de lo que corresponde pagar a cada uno, para que a su vez lo distribuyan entre los vecinos (42).

Intervienen también en los repartos de tierras para su explotación individual. Según el decreto de 4 de enero de 1813 Sobre reducir los baldios y otros terrenos comunes a dominio particular: suertes concedidas a los defensores de la patria y a los ciudadanos no propietarios, son las diputaciones las que proponen a las Cortes las condiciones en que han de efectuarse los repartos de baldíos o realengos, y de propios y arbitrios en sus respectivas provincias, tanto en la Península como en Ultramar, fijando los plazos pertinentes (43).

Afecta directamente a Ultramar la aprobación del Decreto de 9 de noviembre de 1812 por el que se abole la mita y otros servicios personales y se dictan medidas en favor de los indios. Las diputaciones se ocuparán de que reciban tierras los indios

(41) C.D.O. 1810-1814, IV, 244-257. La Secretaría de Gobernación de Ultramar elabora a modo de cuestionario una "Instrucción que han de tener presente las Diputaciones provinciales, los jefes políticos o intendentes de las Provincias de Ultramar, para que con arreglo a ella formen los cuadernos de las visitas que deben hacer segun ordenanza y salgan uniformes y coordinadas bajo un propio método, a fin de poder sacar de sus noticias y relaciones todas las luces y ventajas que se necesitan para dictar las providencias más útiles al fomento de aquellos países". Se trata de un documento que abarca todos los aspectos de la vida ultramarina, desde los demográficos a los económicos, pasando por los religiosos, educativos etc. El cuestionario nunca llegó a cumplimentarse, quedándose como en otros casos en un marco ideal de referencia. Ha sido publicado recientemente al menos en dos ocasiones. Por Silvia VILAR, "Ultimas proyecciones coloniales de la España ilustrada: dos interrogatorios de Indias inéditos (17601812)" Hispania: $\mathrm{n}^{\mathrm{9}}$ 119, págs. 633-655 (Madrid, 1971) y por Francisco de Solano Cuestionarios para la formación de las Relaciones Geográficas de Indias siglo XVIXIX. Colección Tierra Nueva y Cielo Nuevo, Centro de Estudios Históricos CSIC, págs. 205-234 (Madrid 1988).

(42) Las suspicacias y dudas obligan a las Cortes a precisar: por un decreto de 14 de abril de 1814 queda aclarado que el repartimiento del cupo de la contribución directa que corresponde a cada pueblo toca a los intendentes y su contaduría, mientras que su intervención y aprobación si es función de la Diputación provincial. C.D.O., V, 167-168.

(43) Los ayuntamientos señalan los lotes que en sus pueblos han de asignarse a oficiales, soldados y civiles que hayan actuado patrióticamente y remiten el expediente a la Diputación provincial para su aprobación. Ibidem, III, 189-192. 
casados o mayores de 25 años no sujetos a la patria potestad, marcando la porción de terreno a entregar a cada individuo en función de las circunstancias de cada pueblo y del propio beneficiario (44).

Y en un plano mucho más general, podríamos considerar las relaciones de las diputaciones con las Sociedades de Amigos del País que se mantienen como instrumento impulsor del desarrollo económico. En junio de 1812 el diputado Guereña (por Durango) sugería a las Cortes que dado que la Constitución daba a las diputaciones responsabilidad en la promoción de la educación y fomento de la agricultura, industria y comercio, también les correspondiera

Formar reglamentos, que examinará y aprobará el jefe político, para establecer Sociedades Económicas de sujetos respectivamente facultativos, que con sus conocimientos científicos y observaciones, se interesen gratuitamente en el adelantamiento de dichos reynos (45).

Y en esa línea, el 28 de noviembre, las Cortes considerarán que, «La Regencia y diputaciones provinciales excitarán y protegerán el celo de los ciudadanos para que las formen o se adscriban a las ya formadas" (46).

Por último, en esta aproximación a las múltiples competencias de las diputaciones, hay que mencionar dos aspectos que atañen a su participación en el proceso de erradicación de los mecanismos de los que se había servido el Antiguo Régimen para ejercer el poder absoluto. Así por decisión de las Cortes corresponde a las diputaciones o en su defecto a los ayuntamientos, hacerse cargo de los bienes y efectos de los Tribunales del Santo Oficio de la Inquisición: los intendentes de las provincias, con la intervención de las diputaciones - según consta en el párrafo segundo del art. 135 de la Constitución - recogerán y guardarán los inventarios y libros de cuentas, las escrituras y documentos, los papeles relativos a fundaciones de patronatos y cofradías y las nóminas y nombramientos de empleados (47).

(44) Ver el artículo 5 del decreto de 9 de noviembre de 1812 en Ibídem, III, 162 .

(45) D.C.C. 1811-1813, XIII, 412.

(46) Ibidem, XVI, 215. La propuesta sería aprobada meses más tarde, el 26 de abril de 1813.

(47) Se discute en la sesión de 1 de febrero de 1813 y queda aprobado por decreto de 22 de febrero. Ver para el debate D.C.C. 1811-1813, XVII, 94-95 y para la reproducción del decreto C.D.0. 1810-1814, III, 220-224. 
El Decreto de Libertad de Imprenta promulgado el 10 de noviembre de 1810 , por un lado, terminaba con siglos de represión de las posibilidades de expresión oral y escrita y por otro articulaba un sistema de control para hacer frente a los excesos y a la violación de la legalidad. Las Juntas de censura son el mecanismo diseñado a tal efecto. El Reglamento que las regula (de 10 de junio de 1813), dispone que en los niveles más bajos se establezca una red de Juntas provinciales cuya demarcación coincide con la de las diputaciones. Estas últimas se encargarán, usando para ello los fondos de propios y arbitrios, de abonar anualmente la cantidad necesaria para el desempeño de su cometido (48).

\subsection{Relación e interferencias con otras instituciones: audiencias $y$ ayuntamientos}

Las diputaciones provinciales y las audiencias: Son diversas las competencias que sobre administración de justicia recaen en las diputaciones. La audiencia, reformada por las Cortes, ve así como la nueva institución le enajena ciertas funciones y se interfiere en otras. Ya el título $\mathrm{V}$, capítulo $1^{\mathrm{0}}$ de la Constitución hacía depender el número de audiencias de la división territorial en provincias. Ahora, durante la discusión del Proyecto de ley de audiencias que se inicia a finales de julio de 1812, se suscitan diversas cuestiones que en definitiva prueban hasta qué punto las diputaciones eran valoradas por las Cortes. El artículo $1^{\mathbf{0}}$ las hace intervenir en la distribución provisional de partidos en sus respectivas provincias, de acuerdo con las audiencias, para que haya en cada uno de ellos un juez de primera instancia (49); el artículo $3^{9}$ les confiere en Ultramar la tarea de distribuir los partidos teniendo en cuenta que ha de haber un juez de primera instancia en un territorio de más de cinco mil vecinos (50); el artículo $4^{\circ}$ especifica que las diputaciones harán un partido por

(48) Sesión de 20 de mayo de 1813. El Reglamento de Juntas de Censura en C.D.O. IV, 100-105.

(49) D.C.C. 1811-1813, XIV, 241. El texto definitivo es el Reglamento de Audiencias y Juzgados de Primera Instancia que se aprueba el 9 de octubre de 1812.

(50) Más adelante, ya aprobado el texto definitivo, el diputado peruano señor Ribero, al hacer una petición concreta (que el ayuntamiento de Arequipa pase a depender de la audiencia del Cuzco en lugar de la de Lima) se lamenta de que, debido a la lentitud del proceso legislativo, aún no sea un hecho el que en efecto sean las diputaciones provinciales las que propongan la división de partidos más oportuna y que por eso... "las audiencias han de seguir con los territorios que hay hasta que se haga la conveniente división de toda la monarquía: esto no es de esperar, no es posible que se verifique, sino dentro de muchos años". Ver la sesión de 10 de noviembre de 1812 en D.C.C.1811-1813, XVI, 97-98. 
separado si algún territorio o partido ya formado no puede agregarse a otro por localidad o distancia; el artículo $6^{0}$ permite que las diputaciones establezcan el número de subalternos en los juzgados de primera instancia.

En el curso de las discusiones del Proyecto, el 9 de septiembre se trata de una de las funciones de la audiencia, la visita periódica a las cárceles. El señor Argüelles propone (y se acepta su propuesta el día 11) que los magistrados sean acompañados por dos individuos de la diputación provincial en las capitales de provincia, y en los pueblos de primera instancia por dos regidores del ayuntamiento (51). Con la aprobación del artículo $14^{\circ}$ que inhibe a la audiencia de todo conocimiento acerca de los asuntos gubernamentales o económicos en favor de la diputación, culmina el recorte de competencias de las audiencias, quedando abierta la vía de numerosos contenciosos entre ambas instituciones (52).

Las diputaciones provinciales y los ayuntamientos: Especialmente conflictivas fueron sus relaciones, sobre todo a raíz de la promulgación de la ya mencionada Instrucción para el gobierno económico político de las Provincias el 23 de junio de 1813 que definía en el papel las obligaciones que correspondían a ayuntamientos, diputaciones y jefes políticos. Se trataba de articular el funcionamiento y entendimiento de tres piezas clave en el nuevo sistema político. De hecho, los ayuntamientos quedaban supeditados a las otras dos en varios campos de actuación, lo que derivó es el caso del Perú en numerosos enfrentamientos.

El Proyecto de ley comienza a verse en las Cortes a partir del 21 de mayo. A pesar de su trascendencia los artículos van siendo aprobados tal y como los propone la comisión, sin diferencias

(51) Es el artículo LVII que queda redactado "Asistirán sin voto a estas visitas generales, interpolados con los magistrados de la audiencia, después del que las preside, dos individuos de la diputación provincial o del ayuntamiento del pueblo en que reside el tribunal, si no existiese alli la diputación o no estuviese reunida; y con este objeto, la audiencia señalará la hora proporcionada, y lo avisará anticipadamente a la diputación o al ayuntamiento, para que nombren los dos individuos que han de concurrir. C.D.O. 1810-1814, III, 117-118.

(52) Posteriormente encontramos escasas menciones a esta delimitación de competencias: en la sesión de 13 de febrero de 1813, el diputado por Galicia Rodríguez de Bahamonde pide que, en cumplimiento de lo que marca la ley de 9 de octubre de 1812 las diputaciones provinciales se dediquen con particular atención a la distribución provisional de partidos, para que cada uno pueda contar con un juez de primera instancia (D.C.C. 1811-1813, XVII, 225). Para ofrecer una solución momentánea se promulga una orden de 2 de mayo de 1813 Sobre la distribución provisional de partidos $v$ establecimientos de juzgados de primera instancia por la que queda a cargo del intendente y dos individuos del ayuntamiento constitucional hacer las divisiones provinciales de partido, ver C.D.O. 1810-1814, IV, 67-68. 
sustanciales. Los diputados americanos intervienen, pero con un nivel escaso de exigencia.

Entre las pocas mociones aceptadas está la que hace el diputado por Nueva España señor Pino en el sentido de que sean específicamente las diputaciones las que cuiden «que los habitantes de Ultramar dispersos en los valles y montes se reduzcan a vivir en poblados, en conformidad con lo propuesto por las leyes» (53). Sin embargo, por la oposición del señor Argüelles queda pendiente la adición que a dicha propuesta pretende introducir el señor Ramos Arizpe, de que también corra a cargo de las diputaciones de Ultramar el establecimiento de misiones de infieles y nuevas poblaciones de españoles (54).

Del formulismo imperante se separa la intervención el día 5 de junio del señor Larrazábal denunciando lo que considera un peligro de arbitrariedad: al disponerse que la diputación haya de consultar con el gobierno y esperar su autorización para todos los casos y medidas de cierta relevancia, y que todos los recursos y comunicaciones hayan de dirigirse por conducto del jefe político, se quita capacidad de resolución a la institución aumentando el riesgo de que prime la conveniencia personal del individuo que detente tal cargo. Ramos Arizpe coincide con él, mientras Argüelles defiende a la comisión, quedando el artículo aprobado el día 10 sin modificaciones.

El propósito de la Instrucción era obviamente establecer para el gobierno de las provincias un sistema de balanza de poderes que evitara la prepotencia de una institución sobre las demás. Su aplicación (al menos por lo que al Perú se refiere) resultará en un rosario de conflictos cuando cada una trata de apurar al máximo las prerrogativas que la ley le otorga y choca indefectiblemente con las otras.

De hecho, como se ha señalado, los ayuntamientos se ven condicionados en sus actuaciones por el jefe político y las diputaciones. Al primero han de dar cuenta de sus gestiones, sometiéndose a su supervisión. A las diputaciones han de rendir anualmente cuentas documentadas del uso que hacen de los recursos con que cuentan (caudales de propios y arbitrios), teniéndolas al tanto de la administración de esos fondos a través del jefe político.

(53) D.C.C. 1811-1813, XVIII, 397, sesión de 1 de junio de 1813. Es el artículo XVI del Cap. II de la Instrucción.

(54) Ramos Arizpe renovaría su demanda en la sesión del 19 de junio sin resultado positivo. 
Las probabilidades de choque aumentan al compartir ambas instituciones una serie de obligaciones: promoción de la educación mediante la creación de escuelas, fomento del desarrollo económico, plan de obras públicas... Por si fuera poco, son las diputaciones las que han de ocuparse del establecimiento de ayuntamientos en aquellos pueblos donde -cumpliéndose los requisitos- aún no los hubiere. Y aún por encima de ellas, el jefe político al que la Instrucción convierte en el único conducto de comunicación entre ayuntamientos y diputaciones y entre ambas y el gobierno central (55).

\subsection{Las diputaciones provinciales y la representatividad}

A lo largo de este trabajo se ha insistido en cómo la fijación del número de diputaciones provinciales en Ultramar fue una de las cuestiones más controvertidas y que suscitaron una mayor polémica. Al peligro de federalismo que según la mayoría de los diputados peninsulares entrañaba su proliferación excesiva, había que añadir un riesgo adicional: el aumento de diputaciones provinciales estaba en relación con el número de diputados americanos en las Cortes. Es decir, nos topamos con el problema de la representatividad que dividió especialmente a los diputados de ambos lados del Atlántico y cuya resolución sería entendida por los americanos como prueba de discriminación (56).

En efecto, una de las tareas de las diputaciones era intervenir en la elección de los diputados a Cortes. El título III de la Constitución (en sus capítulos II, IV y V) fijaba el procedimiento a través de tres canales sucesivos: las Juntas de Parroquia (los ciudadanos residentes mayores de 25 años, laicos o del clero secular votaban a un elector por cada 200 residentes con derecho a voto mediante un escrutinio oral), las Juntas de Partido (los electores parroquiales se trasladaban a la cabeza de partido para

(55) D.C.C. 1811-1813, XX, 75 y 137-145. Se contempla en el artículo 19 del Proyecto que corresponde al artículo XVII de la Instrucción. Posteriores consultas y numerosos roces dan lugar a sucesivas puntualizaciones. El 11 de agosto de 1813 se publican Varias reglas para el gobierno de las diputaciones provinciales y ayuntamienios de los pueblos. Se precisa por ejemplo, que los individuos que sustituyan a los intendentes en sus destinos, harán las veces de estos en las diputaciones provinciales, pero no podrán presidirlas; pueden ser elegidos diputados a Cortes o niembros de las diputaciones provinciales quienes ejerzan cargos concejiles, pero al tomar posesión, los habran de dejar vacantes (tanto en la Península como en Ultramar). Ver C.D.O. 1810-1814, IV, 174.

(56) J. KING, "The colored castes and american representation in the Cortes of Cadiz" Hispanic America Historical Review vol. XXXIII, n 1, págs. 33-64 (1953). 
integrarla y elegir a su vez a los electores a nivel provincial entre los ciudadanos residentes mayores de 25 años que fueran propietarios de tierras $\mathrm{u}$ otros inmuebles) y finalmente esas Juntas de Provincia elegían a los diputados a Cortes.

El sistema electoral va desarrollándose con posterioridad. Para el caso americano, el primer paso es la Instrucción conforme a la cual deberán celebrarse en las Provincias de Ultramar las elecciones de Diputados a Cortes para las ordinarias del próximo año de 1813 (publicada el 23 de mayo de 1812). Dispone la formación de Juntas preparatorias compuestas por el jefe político, el arzobispo, el intendente (si le hay), el alcalde más antiguo, el regidor decano, el síndico procurador general y dos hombres de la provincia nombrados por los anteriormente citados. En América las juntas se instalarán en quince capitales: México, capital de Nueva España; Guadalajara, capital de la Nueva Galicia; Mérida, capital de Yucatán; Goatemala, capital de esa provincia; Monterrey, capital del Nuevo Reino de León; Durango, capital de Nueva Vizcaya; La Habana, capital de Cuba y de las dos Floridas; Santo Domingo, capital de dicha isla; Santa Fe de Bogotá, capital de Nueva Granada; Caracas, capital de Venezuela; Lima, capital del Perú; Santiago, capital de Chile; Buenos Aires capital del Río de la Plata, y Manila, capital de Filipinas. La misión inicial de las Juntas preparatorias es distribuir - provisionalmente- el territorio en provincias y éstas a su vez en partidos (en caso de que no estuvieran señalados). Deberán asignar según la población y tomando como base un diputado por cada 70.000 personas de las comprendidas en el artículo 29 de la Constitución, el número de electores que a cada provincia corresponde. Además habrán de resolver las dudas que puedan presentarse en relación con la formación de diputaciones provinciales. Cesarán en sus funciones cuando estén formadas las Juntas electorales y comiencen a celebrarse elecciones (57).

Simultáneamente, también el mencionado Decret॰ sobre el Establecimiento de Diputaciones provinciales en la Peninsula y Ultramar, de la misma fecha que el anterior, regula el procedimiento para elegir temporalmente a los miembros de la diputa-

(57) Durante la discusión de la Instrucción, en la sesión de 11 de mayo de 1812, el diputado Mexía había hecho notar la conveniencia de que se instalaran Juntas preparatorias en varias capitales del Perú en las que no se hace mención en la Instrucción, y el diputado Rus aprovecha para recabar de nuevo el derecho de Maracaibo a contar con una Diputación provincial propia. D.C.C. 1811-1813, III, 246. 
ción provincial en tanto se verifique la distribución definitiva del territorio. Hasta entonces

No habiendo de haber diputaciones en todas aquellas en que se hará la elección de diputados a Cortes, donde esto suceda, los individuos de la diputación provincial serán nombrados en las capitales de las provincias comprehendidas en el territorio de la diputación.

Las juntas electorales de provincia se harán cargo del proceso: si hay siete provincias en el territorio de la diputación, cada una nombrará un miembro (del modo que se estipula en el artículo 328 de la Constitución); si hay menos de siete, nombrará a uno o más miembros hasta completar el total, dando ventaja a la provincia con mayor número de habitantes; si por el contrario el número de provincias es superior a siete la primera vez nombrarán las que tengan mayor población, en el segundo bienio intervendrán las que no lo hicieron, y para completar el número, si hace falta, de nuevo participarán las provincias de más habitantes. Siempre ha de haber en la diputación un individuo de la capital o su partido, y turnarán en las elecciones todos los partidos en que se halle distribuida la provincia (58).

Para hacer efectivos los procedimientos enumerados es necesario introducir cambios en otra institución básica, el ayuntamiento, poniendo fin a los cargos en perpetuidad y sustituyéndolos por electivos. El Decreto de Formación de los Ayuntamientos constitucionales de 23 de mayo de 1812 dispone que el número de integrantes en los cuadros de los ayuntamientos esté en relación con el de vecinos, pudiendo oscilar entre un alcalde, dos regidores y un procurador síndico en aquellos pueblos que no pasen de 2.000 vecinos, a dos alcaldes, doce regidores y dos síndicos en los que cuenten con más de 4.000. El sistema de elección es por supuesto censitario y parte, como en el caso de los diputados a Cortes, de las Juntas de Parroquia a partir de las cuales se forma la Junta de electores presidida por el jefe político y si no lo hubiera por el alcalde más antiguo o en su defecto por el regidor más antiguo. Se atiende a las circunstancias especiales que pueden darse en Ultramar

Como puede suceder que haya en las provincias de Ultramar algunos pueblos que por sus particulares circunstancias deban

(58) Ver el artículo II del Decreto en C.D.O. 1810-1814, II, 225-226. 
tener ayuntamientos para su gobierno, pero cuyos vecinos no estén en el ejercicio de los derechos del ciudadano, podrán sin embargo en este caso elegir entre sí los oficios del ayuntamiento bajo las reglas prescritas en esta ley para los demás pueblos (59).

Finalmente, la Instrucción para el gobierno económico y politico de las provincias de 23 de junio de 1813 pone en marcha todo este complejo mecanismo electoral fijando para el último domingo de noviembre de 1813 en Ultramar, y el último domingo de septiembre de 1814 para la Península y posesiones adyacentes, y así sucesivamente cada dos años, para que se conformen las juntas electorales de parroquia que nombren al elector o electores que corresponden al pueblo y que han de concurrir a las elecciones de partido. Corre a cargo del individuo que presida el ayuntamiento el informar de cada paso a los vecinos con derecho a voto y dar parte al jefe político de los resultados de las elecciones (60).

Cumplido el proceso hasta el último estadio, los diputados a Cortes habrán de incorporarse a sus tareas, y en caso de que alguno esté en imposibilidad absoluta de hacerlo, habrán de justificarlo ante los jefes políticos adjuntando un informe de la diputación provincial, o, si no está reunida, del ayuntamiento del pueblo de residencia del diputado (61).

\subsection{Proyección inicial de las diputaciones provinciales en América}

La información que sobre el establecimiento y evolución de la diputación provincial en América proporciona la documentación peninsular es poco abundante. En los Diarios de Sesiones de las Cortes aparecen noticias indirectas y esporádicas. Hay que tener presente la irregularidad de las comunicaciones, dificultadas por el estado de insurgencia en que se hallaban zonas importantes como Chile o Venezuela, y la independencia de hecho alcanzada por otras como el Río de la Plata.

Con relación a Venezuela es preciso recordar que el año que se establece la institución (1813) es de puente entre la primera y segunda repúblicas. Los realistas se han hecho transitoriamente

(59) Se trata del artículo XII del Decreto de Formación de Ayuntamientos constitucionales. Ver Ibidem, 224.

(60) Ibidem, IV, 119.

(61) Decreto de 16 de noviembre de 1813, Ibidem, V, 25-26. 
con la situación y para apuntalarla el diputado por Maracaibo señor Rus pide insistentemente a las Cortes que se tome en cuenta la importancia de devolver la tranquilidad a aquellas provincias mediante la instalación de ayuntamientos y diputaciones provinciales (62). En diversas ocasiones y en el curso de la discusión de los distintos proyectos sobre el gobierno no político y económico este diputado había demandado la instalación de una diputación en Maracaibo para completar, y en casos suplir, a la de Caracas.

Más numerosas son las noticias sobre Cuba y Puerto Rico. En la sesión de las Cortes de 29 de enero de 1813 los cubanos Jáuregui y O'Gavan informan del establecimiento en julio del año anterior de la junta preparatoria que habría de facilitar las elecciones a diputados a Cortes y la formación de diputaciones provinciales. En la sesión de 20 de mayo se da cuenta de que ha pasado a la comisión de Constitución la certificación del acta de instalación de una diputación en Santiago de Cuba, dirigida por el gobernador de aquella provincia Don Pedro Suárez de Urbina (63).

El 16 de julio se expide una orden Sobre la elección de Diputados a Cortes y Diputación Provincial de la Isla de Cuba que ratifica la formación de dos diputaciones, en La Habana y en Santiago de Cuba, y establece el sistema de renovación de los miembros de La Habana (64). El día 27 Jáuregui informa de la instalación de la diputación de La Habana sin precisar fecha.

En cuanto a Puerto Rico, el 5 de agosto de 1813 las Cortes pasan a la comisión de Constitución un oficio del Secretario de la Gobernación de Ultramar que comunica haberse instalado en la Isla de la diputación (65).

Sin duda los casos mejor conocidos son los de las diputaciones provinciales en Nueva España y Guatemala. Sabemos que el virreinato llegó a contar con siete diputaciones, incluyendo las de Guatemala. La primera en surgir fue la de Mérida de Yucatán el 23 de abril de 1813, incluyendo los actuales territorios de Yucatán, Campeche y Tabasco; le suceden la de Guatemala el 2 de septiembre, provincias de Guatemala y Chiapas; Nueva Galicia

(62) D.C.C. 1811-1813, XVIII, 439, sesión de 26 de abril de 1813.

(63) Ibidem, XIX, 316-317.

(64) C.D.O. $181--1814$, IV, 147.

(65) Uno de los miembros es el presbítero de la diócesis de Puerto Rico don Antonio Sánchez. En la sesión de 6 de mayo de 1813 se ve su renuncia para la que alega que no puede ejercer tal puesto por prohibirlo específicamente un decreto de 21 de septiembre de 1812 . 
el 20 de septiembre (provincias de Nueva Galicia y Zacatecas); Provincias Internas de Oriente el 21 de marzo de 1814 (Nuevo León, Coahuila, Nuevo Santander y Texas); Nueva España el 13 de julio (México, Michoacán, Oaxaca, Veracruz, Puebla, Tlaxcala y Querétaro); San Luis de Potosí (San Luis de Potosí y Guanajuato) y las Provincias Internas de Occidente (Durango, Chihuahua, Sinaloa, Sonora y Nuevo México) (66). Las intervenciones continuas de los diputados mexicanos, y sobre todo la actuación de Ramos Arizpe, debieron sin duda repercutir en ese número, abultado si lo comparamos con el resto de los territorios ultramarinos.

En cuanto al Perú, la información es muy escasa. Los datos proporcionados por el doctor Alfredo Moreno Cebrián que prepara una investigación exhaustiva sobre la Diputación Provincial de Lima revelan que ésta se instaló formalmente el 30 de abril de 1813 en presencia del virrey Abascal, el intendente de Lima Gálvez, y el diputado electo - también por Lima- Francisco de Moreyra, siendo secretario José Herrera y Sentmanat. Celebra sesiones hasta el 6 de octubre de 1814, y su labor se desarrolla en la resolución de expedientes de trámite, aunque también aquí se reproducen las tensiones entre el virrey y los demás miembros así como con el ayuntamiento constitucional. Es también segura la existencia desde finales de 1813 de una Diputación en el Cuzco, porque está presente en la elección a diputados a Cortes por la demarcación (67). No sucede aquí como en Nueva España, la estructuración político administrativa de la república peruana no se vincula directamente a las diputaciones (68).

Pero no es el propósito de este trabajo hacer un seguimiento de la diputación provincial en Indias, sino encuadrarla en el marco de la renovación institucional que llevan a cabo las Cortes de Cádiz. Como en otros casos que podrían ponerse como ejemplo, el sistema liberal español utilizó raseros diferentes en la Península y en América (69). Ahora estaba en juego el sistema de gobierno político-económico de las provincias. La vuelta al absolutismo truncó cualquier posible alternativa.

(66) BENSON [7], pág. 43. No da fechas de instalación para San Luis de Potosí y las Provincias Internas de Occidente.

(67) Colección Documental de la Independencia del Peri, tomo IV, vol. 2. Lima 1971, págs. 428-431.

(68) Demarcación Politica del Perú. Recopila inn de Leyes y Decretos. Lima, 1946, págs. 116-117.

(69) Ascensión Martínez Riaza, "La proyes:... clel liberalismo gaditano en Anérica, nexos y desconexiones". Cádiz e Iberoullírica, n 6, págs. 7-17 (Cádiz. 1988). 


\section{LAS DIPUTACIONES PROVINCIALES AMERICANAS EN EL TRIENIO LIBERAL}

\subsection{La "cuestión americana» en las Cortes: desinformación y relegamiento}

Las sesiones de las Cortes son, sin duda, uno de los indicadores a pulsar para seguir las contingencias de la política española, en relación a Ultramar. La problemática americana está presente de una forma bien distinta a como lo había hecho en el anterior período constitucional. La "cuestión americana" se centra en el modo de encarar una situación que amenaza con liquidar a la "nación española» tal como estaba delineada en la Constitución de 1812. Asistimos a un proceso en el cual cada vez se discute menos sobre cómo gobernar los territorios americanos y más sobre cómo mantenerlos. El tratamiento que reciben asuntos de organización y funcionamiento interno - es el caso de las Diputaciones provinciales- es cada vez más limitado y esporádico, llegando a desaparecer prácticamente en los primeros meses de 1822 coincidiendo con el abandono de sus escaños por parte de la mayoría de los diputados ultramarinos.

Durante el Trienio se hace norma la legislación aprobada por sendos decretos de 8 de abril y 4 de septiembre de 1813, que disponía que los distintos ministros habían de presentar al comienzo de las legislaturas una Memoria del estado de su parcela al hacerse cargo de ella. Es característico que los diferentes responsables de Ultramar repitan en sus alocuciones ante la Cámara el mismo argumento: sus posibilidades de actuación se ven cortocircuitadas por la escasa información de la que disponen, lo que les impide tomar medidas eficaces.

Los Diarios de Sesiones corroboran lo apuntado. Las noticias que sobre América proporcionan son dispersas y de importancia desigual. Van desde cuestiones puntuales, como dar cuenta de haberse jurado la Constitución y restablecido las fórmulas liberales en distintos lugares, a asuntos de mayor envergadura como la resurrección del tema de la representatividad, viejo caballo de batalla de los diputados americanos. Se advierte además un creciente retraso en la divulgación de la información relacionada con la fecha en que se produce.

Lo que es indiscutible es que el sistema no funciona, ni siquiera en las regiones aún fidelistas: la maquinaria que regula la elección de los nuevos representantes a Cortes se ve obstaculizada 
por fallos básicos en los engranajes que se traducen en irregularidades en la celebración de elecciones - ya pormenorizadamente estructurado desde el perído anterior - y en dificultades para recaudar fondos con qué sufragar el traslado y dietas de los diputados.

La representación efectiva de los americanos en las Cortes se va reduciendo progresivamente y con ella disminuye su capacidad reivindicativa, a ello contribuye el estado consumado de "rebeldía» en muchos territorios. La labor legislativa sigue su curso aún en medio de fuertes tensiones internas, como prueban las leyes que abolen los mayorazgos y monopolios, las que reforman el clero regular y los códigos penal y de trabajo, agricultura y comercio (70). Pero, y hay que enfatizarlo, las medidas y disposiciones atañen cada vez más a la Península $\mathrm{y}$, en menor medida, a Ultramar.

El contenido de las primeras Memorias de los Secretarios de Estado y del despacho de Gobernación de Ultramar, no ofrece sino una panorámica general y superficial de la situación americana (71). Ante las voces de alarma, provenientes sobre todo de diputados americanos como el bonaerense Magariños, que advierten de la progresiva insurgencia en América del Sur, en mayo, las Cortes instan al titular responsable a dar cuenta en extenso de lo que realmente acontece. Presionado, éste ha de admitir que carece de información y que los únicos datos completos con que cuenta, se refieren a Cuba (72).

Surgen desde el poder una serie de iniciativas que ponen en primer plano las diferencias entre el legislativo, el Consejo de Estado, creado en marzo y compuesto por cuarenta miembros, de ellos doce americanos, y el Ministerio de Ultramar. Una de las primeras es la designación en junio de comisarios para negociar en América (73). Ya en las Cortes, a instancias del conde de Toreno, se constituye en mayo una comisión formada por cuatro peninsulares y cinco americanos (un venezolano y cuatro mexicanos) cuyo cometido es elaborar un proyecto de paz para Amé-

(70) Raúl Morodo y Elías Díaz, "Tendencias y grupos políticos en las Cortes de Cádiz y en las de 1820". Cuadernos Hispanoamericanos, n 201, págs. 637-675 (Madrid, 1966).

(71) Ver como ejemplo la presentada por Ramón Gil de la Cuadra en la sesión de 6 de marzo de 1821. En Diario de Sesiones de las Cortes 1820-1823, Imprenta J. A. García, Madrid 1871-1875, legislatura 1821, tomo I, págs. 121-139.

(72) Sesión extraordinaria de 10 de mayo de 1821.

(73) Timothy ANnA, España y la Independencia de América, Fondo de Cultura Económica, págs. 276-278, México, 1986. 
rica. A la hora de presentarlo, los americanos comprueban con preocupación que sus puntos no son tenidos en cuenta $\mathrm{y}$, en la sesión de 25 de junio, ofrecen como alternativa conjunta la creación en América de tres secciones de las Cortes con sede en México, Santa Fe y Lima, acompañadas de la correspondiente delegación del ejecutivo, tres secciones del Tribunal Supremo de Justicia y del Consejo de Estado y en cada una de ellas cuatro ministerios (Gobernación, Hacienda, Gracia y Justicia y Guerra y Marina). A pesar de que se trataba de la propuesta de los más directamente afectados, las Cortes se inclinan por la opción del conde de Toreno, mientras el ejecutivo la rechaza por ver en ella un peligro de federalismo (74).

La causa de los diputados americanos pierde fuerza durante la legislatura extraordinaria que se extiende del 22 de septiembre de 1821 al 14 de febrero de 1822. Para entonces su número asciende a 78 entre propietarios y suplentes, pero los peninsulares se oponen a la concurrencia de los últimos por entender que no se cumplían las normas legales. Mientras, la "cuestión americana» pierde protagonismo en beneficio de los problemas internos de la península. En octubre, el diputado señor Paul renueva la petición de que comparezca el Secretario con la información pertinente. Así lo hace durante los días 13 y 14 de diciembre, pero de nuevo su dictamen es muy general, para salir del paso, y sus palabras traducen ante todo desconocimiento e impotencia. Tanto es así, que el señor Navarrete denuncia que la prensa es capaz de proporcionar a la opinión pública más información que el responsable político, a través de ella se conoce por ejemplo que en Nueva España y Centroamérica la independencia es un hecho que, sin embargo, el gobierno parece soslayar (75).

Paralelamente a la labor del legislativo, también el ejecutivo delibera y propone. En noviembre de 1821, el Consejo de Estado, para limar asperezas, of rece la suspensión de aquellas medidas que más podrían ofender a los americanos y da una serie de recomendaciones que incluyen el envío de sendas escuadras al Callao y Veracruz, la posibilidad de acudir a la mediación británica, la liberalización del comercio y el procurar por todos los medios que América envíe delegados a las Cortes para la legislatura 1822-1823. El gabinete las suscribe en lo fundamental, y en enero aconseja a las Cortes la adopción de una política concilia-

(74) Alberto Gil. Noval.ls, El Trienio) Liberal, Siglo XXI, pág. 31 (Madrid, 1980).

(75) D.S.C. 1820-1823, Leg. sept. 1821 -feb. 1822, tomo II, págs. 1.302-1.303. Sesión de 15 de diciembre de 1821 . 
dora que pasa por un armisticio de dos años, la liberalización del comercio durante seis años y la mediación extranjera. Sin embargo, la propuesta es rechazada por la comisión para Ultramar de las Cortes el 24 de enero de 1822 (76).

Casi al final de esta legislatura, en la sesión de 27 de enero de 1822 se lee la propuesta del militar liberal Miguel Cabrera de Nevares que, partiendo de la necesidad de que el gobierno español reconozca la independencia de hecho de los territorios americanos, sugiere la creación de una Confederación de Estados Hispanoamericanos con un Congreso Federal y Fernando VII como protector. Las tensiones crecientes entre la Comisión de Ultramar y el ministerio, se reflejan en los duros debates que tienen lugar en la legislatura que se celebra del 15 de febrero al 30 de junio de 1822. Resurge la propuesta del envío de comisionados perfilada por el conde de Toreno que se complementa con su adición de que, de ningún modo, se reconozca la independencia, ni tengan representación en Cortes aquellas provincias que se declaren manifiestamente rebeldes (punto éste retirado de los debates por la reacción airada de los diputados americanos). Por su parte, la comisión de Asuntos de Ultramar, formada en el momento por los señores Espiga, Cuesta, Alvarez Guerra, Toreno, Moscoso, Oliver, Murfi, Navarrete y Paul, es partidaria de sentar unas bases de negociación, hasta que se establezcan deben considerarse nulos todos los tratados celebrados entre las autoridades españolas y los jefes americanos. Particularmente Moscoso y Toreno advierten que, en cualquier caso, sería perjudicial reconocer la independencia de las provincias de Ultramar antes de que se establezcan con ellas tratados que aseguren ventajas políticas y comerciales para la Madre Patria respecto a las naciones extranjeras (77).

En efecto, las vías de negociación se estrechan por momentos. Entre los diputados peninsulares, con Canga Argüelles como portavoz, se afirma la tendencia favorable a tratar como independientes a aquellos territorios que hayan adquirido la suficiente estabilidad como tales (78). El 25 de junio de 1822 se lee el dictamen de la Comisión de Ultramar acerca de la última Memoria presentada por el Secretario de Despacho de la gobernación

(76) Timothy ANNA, "Institutionals and politician impediment o Spain's settlement of the american rebelion", The Americas, vol. XXXVIII, no 4, pág. 493 (1982).

(77) D.S.C. 1820-1823, legislatura sept. 1821-feb. 1822, tomo III, págs. 2.2722.273 y 2.297 , Sesiones del 12 y 13 de febrero de 1822 .

(78) D.S.C. 1820-1823, legislatura 1822, tomo I, Sesión de 7 marzo de 1822. 
del Reino para aquellas provincias. En un diagnóstico general, hace un repaso del estado de todas las regiones; entre las insurgentes, sólo el Perú puede tener solución si se envían socorros marítimos. Da por sentada la independencia de la mayoría de los territorios y propone se concentren los esfuerzos en proteger los intereses metropolitanos en Cuba y Puerto Rico. Las Cortes aprueban el dictamen (79). Sin embargo, el decreto promulgado por el gobierno el día 28 es revelador de la actitud oficial que se resiste a reconocer lo evidente: dispone que se adopten medidas de protección hacia los habitantes aún leales a la monarquía y mantiene la necesidad de enviar comisionados con prerrogativas únicamente en el ámbito de las relaciones comerciales.

Cuando en octubre de 1822 se abre la legislatura extraordinaria que se cerrará en febrero de 1823 , sólo hay en las Cortes representación de Cuba, Guatemala (aunque el diputado abandonaría el escaño), Puerto Rico y Filipinas. Las sesiones prueban la polarización de la atención en la caótica situación del país (inestabilidad entre los militares, consecuencias de las medidas desamortizadoras...) y las propuestas inquietantes de la Santa Alianza. La información sobre Ultramar, reducidísima, se refiere a Cuba y Puerto Rico. Ha desaparecido en las agendas de los diputados la independencia de los territorios continentales. El fin de la legislatura coincide con el golpe de efecto fallido de Fernando VII de cambiar el gobierno.

Las Cortes que se reúnen de febrero a marzo de 1823 tienen como casi único propósito preparar el traslado del Rey y de las Cortes a Sevilla. Con todo, sorprendentemente, se detienen en iniciar la discusión del nuevo proyecto de instrucción para el gobierno económico-político de las provincias de Ultramar. Al efecto, el 2 de marzo se nombra una comisión de Ultramar compuesta por los señores Alava, Sánchez, Varela, Meléndez, Quiñones, Alcántara, Brincas y Murfil (80). A partir de ahora, como señala Gil Novales, el país se pierde irremisiblemente. El proyecto liberal moderado ha fracasado y con las tropas francesas en territorio español, se asiste a una persecución imparable de liberales hacia demócratas a los que culpan de la ruina nacional y a la vez a la represión absolutista contra esos liberales (81). Aún en Sevilla y luego en Cádiz, unas Cortes muy mermadas se

(79) Ibidem, III, págs. 2.156-2.167.

(80) D.S.C., legislatura 1823 I, pág. 7.

(81) A. Gil Novales [74]pág. 57. 
reúnen entre el 23 de abril y el 18 de septiembre. Se dedican, fuera de toda insertación en la realidad, a completar leyes y lamentarse de la situación del país.

Cuando la invasión francesa termine nuevamente con la experiencia liberal y el resucitado Consejo de Indias revoque en diciembre con todos los acuerdos de las legislaturas constitucionales concernientes a la pacificación y gobernación de las provincias estarán disponiendo sobre el papel (82).

\subsection{Restablecimiento de las Diputaciones Provinciales $e$ innovaciones en su estructura}

Con la jura por el Rey de la Constitución el 7 de marzo de 1820 , se reinstauran las fórmulas e instituciones del liberalismo doceañista. Por lo que a las diputaciones provinciales respecta, en la sesión de las Cortes de 11 de julio, en su informe sobre el Gobierno Político Económico del Reino, Agustín Argüelles, anuncia que inmediatamente se restablecerán en la Península las que existían en 1814. Entre las distintas comisiones que se forman en la Cámara, una se ocupa del «Examen de Cuentas y asuntos de las Diputaciones Provinciales» (83).

La diputación provincial sigue siendo una pieza clave en el sistema de gobierno político económico. Durante el Trienio, más aún que en la etapa anterior, es la diputación peninsular la que acapara la atención y copa discusiones y medidas legislativas. Desaparecida - aunque no definitivamente- la amenaza francesa, las Cortes cuestionan ciertos aspectos de la organización doceañista. En lo que se refiere a las diputaciones, se va a poner en tela de juicio su excesiva sujeción al gobierno de la provincia y la insuficiente definición de sus competencias.

(82) William S. RoberTSON, "The policy of Spain Towards its revolted colonies 1820-1823" H.A.H.R. IV, 1926, págs. 38-45. Ver también: Alberto GIL Novales, "La Independencia de América en la conciencia española 1820-1823", Revista de Indias, nos. 157-158, págs. 235-265 (Madrid, 1979) y Jaime DelGADo, "La política americanista de España en el Siglo XIX" en Cuadernos Hispanoamericanos, 2, págs. 29-49 (Madrid, 1948).

(83) Constituida en la sesión de 10 de julio, está compuesta por los diputados Quintero, Martín Tauste, López Artieda, Cavalieri, José Antonio López, Lobato y el mexicano Ramos Arispe, gran defensor de la institución. La Comisión se renueva el 6 de noviembre con el cometido de preparar trabajos en el intermedio de la legislatura, se mantiene Ramos Arispe y entra el suplente por Michoacán Cortázar, el resto son peninsulares. Al iniciarse la legislatura de 1821 hay una nueva reorganización, todavía permanece Ramos Arispe como único americano, en la sesión de 8 de octubre de 1821 se notifica que ha viajado a su país. 
La propuesta de reforma surge de las propias diputaciones peninsulares que reclaman la modificación de la Instrucción de 1813. Habrá que esperar hasta el 3 de febrero de 1823 para que las Cortes Extraordinarias, tras haber observado las formalidades prescritas por la Constitución, promulguen la Ley para el gobierno económico-político de las provincias que deroga la anterior de 23 de junio de 1813. En sus cuatro capítulos y 291 artículos regula las competencias y relaciones de ayuntamientos (arts. 1-82), diputaciones provinciales (arts. 83-182), alcaldes (arts. 183-237) y jefes políticos (arts. 238-290). La estructura es paralela a la Instrucción derogada, pero el contenido del articulado recoge las peticiones más apremiantes de las diputaciones. En lo fundamental, intenta establecer una delimitación más clara entre las competencias administrativas y económicas asignadas a los ayuntamientos y diputaciones, y las funciones políticas y de orden público, a alcaldes y jefes políticos. La diputación provincial, que pasa a ser considerada como el «ayuntamiento general de la provincia", se entiende directamente con los ayuntamientos de su territorio desapareciendo la interferencia del jefe político, además se ocupa de los recursos electorales de los municipios. El jefe político la sigue presidiendo con voto (84).

En cuanto a Ultramar, las noticias relativas al restablecimiento de las diputaciones son dispersas, escuetas y, en términos generales, poco precisas. El caballo de batalla de los representantes americanos continúa siendo el aumento de su número para que la institución responda más adecuadamente a la realidad de aquellos territorios. La reivindicación central es que exista una diputación provincial en cada una de las intendencias. En la sesión de 17 de marzo de 1821, los diputados Ramos Arispe, López Constante, Zabala, La Llave, Maniau, Pierola, Freire, Fagoaga, Arnedo, Urruela, Michelena, Cortázar, Montoya y Couto, piden en estos térmiños una medida general:

Siendo indudable que cada intendencia de Ultramar tiene el carácter y es de hecho una verdadera provincia, habrá desde luego, según el artículo 325 en cada una de dichas intendencias en que no esté ya establecida, una Diputación Provincial para promover su prosperidad. Los electores provinciales se unirán para hace la elección de los individuos que falten para componerla, según el artículo $326(85)$.

(84) Para seguir estos cambios generales ver C. DE CASTRo [8], págs. 95-102.

(85) D.S.C. Leg. febrero-junio 1821 I, 521-522. 
Pocos días después, se vuelve a leer la propuesta. Actúa como portavoz Ramos Arizpe, que insiste en el argumento anterior (86). A finales de abril, las Comisiones de Ultramar y Diputaciones Provinciales dan cuenta de su dictamen acerca de esta cuestión, quedando su vista para el día 30 (87). Así sucede en efecto. Ramos Arispe en nombre de la comisión, inicia el debate rompiendo una lanza a favor de su propio territorio. Para Nueva España, entiende, la situación se presenta favorable, ya que Juan O'Donoju, sucesor del virrey Apodaca, puede encargarse de llevar la orden de la instalación de nuevas diputaciones. Los representantes de Guatemala, Hermosilla y Milla, se unen con sus intereses provinciales, advirtiendo que hasta que no se establezcan las justas diputaciones provinciales "no se aquietarán los disidentes». En la oposición, el peninsular Martínez de la Rosa trata de detener la discusión hasta que pueda comparecer el Secretario de Ultramar, ausente, porque aun cuando las dos comisiones hayan procedido correctamente, no pueden suplir el conducto oficial que es el gobierno. Añade otro argumento; parece que "se ha nombrado ya una comisión en América con el objeto de arreglar una división territorial que debe servir de base para la posterior resolución de estos puntos». Con todo, las Cortes deciden seguir adelante. En el dictamen, las Comisiones insisten en el derecho constitucional que tienen las provincias a contar con una diputación provincial y proponen a la consideración de las Cámaras cuatro puntos:

1.-(que) se establezca una Diputación Provincial en cada una de todas las intendencias de provincia de la España ultramarina en que no esté establecida: la residencia de cada una de todas las Diputaciones Provinciales es la capital de la intendencia respectiva, y su territorio el que actualmente tiene cada una de dichas intendencias.

2.-Continuarán siendo por esta vez individuos de estas diputaciones, como también de las ya establecidas, el que o los que hayan sido nombrados para tal destino en las últimas juntas electorales de provincia celebradas dentro del terrìtorio de cada intendencia.

3.-Para completar el número de individuos que según la Constitución deben componer cada una de todas las Diputaciones Provinciales, los electores de partido que en todo el distrito de cada una de las intendencias hayan formado las últimas juntas

(86) Ibídem, pág. 590, Sesión de 21 de marzo de 1821.

(87) Ibídem, págs. 1.287 y 1.299 . Sesiones del 26 y 27 de abril, respectivamente. 
electorales de provincia para nombrar diputados de Cortes para los años de 22 y 23 , se reunirán en la capital de la intendencia en el día que señalará el jefe político y nombrarán los que falten hasta completar el número de propietarios y suplentes que fija la Constitución en los artículos 226 y 329.

4.-En los ulteriores bienios las elecciones y renovaciones de individuos de las Diputaciones Provinciales, se harán con arreglo a la Constitución y leyes vigentes.

Martínez de la Rosa se cree en la obligación de hacer dos precisiones extraídas de la propia Constitución: la primera, que para componer la diputación provincial, ha de haber necesariamente dos jefes nombrados por el gobierno, uno el jefe político de la provincia, que es el jefe nato, y otro el intendente; la segunda que en las capitales donde haya de haber Diputación Provincial, deben reunirse los electores a diputados a Cortes, porque al día siguiente a esa elección, debe hacerse la de los individuos de la diputación.

Le da la réplica por la Comisión Moreno Guerra: la propuesta observa rigurosamente la Constitución, y se evita «la causa de que en ningún tiempo pueda la América decir que la Europa la ha abandonado ni la ha engañado». Finalmente el dictamen será aprobado (88). La cuestión continuará viva durante todo el mes de mayo. En la sesión del día 10, el diputado señor Milla se lamenta de que la ausencia de noticias sobre el estado de las provincias de Ultramar trabe la posibilidad de acometer la división territorial, las Cortes deciden, en vista de ello, reimprimir la circular de 31 de enero que pide a jefes políticos y diputaciones enviar la información precisa (89).

La culminación del proceso es la promulgación, el 8 de mayo, del Decreto sobre Establecimiento de Diputaciones Provinciales en las provincias de Ultramar donde no las haya, que recoge los cuatro puntos del dictamen. En la sesión de 17 de mayo, las Cortes ordenan repartir entre los señores diputados 200 ejemplares de la circular expedida por el ministro de Gobernación de Ultramar a los jefes políticos de aquellas provincias, insertando el decreto de las Cortes.

A partir de entonces, y hasta el 16 de marzo de 1823 en que se inicia la discusión del proyecto de «Instrucción para el Gobierno Económico-político de las Provincias de Ultramar", todas las

(88) Toda la discusión en Ibidem, págs. 1.357-1.364. Sesión Extraordinaria de 30 de abril de 1821 .

(89) Ibidem, págs. 1.543-1.544 y Sesión de 10 de mayo. 
referencias a la división territorial atañen a la península e islas adyacentes (90). Hasta la Memoria leída ante las Cortes por el Secretario de Estado y del Despacho de Ultramar en la sesión del 6 de marzo de 1821, no hay constatación oficial directa sobre el restablecimiento de las Diputaciones provinciales en los territorios americanos. En el apartado «Gobierno» da cuenta de que,

En las provincias de Nueva España y Guatemala, en las de Venezuela, Panamá y Cartagena de Indias, en las islas de Santo Domingo, Puerto Rico y Cuba se ha jurado la Constitución y nombrado ayuntamientos constitucionales; se han elegido diputados y formado las Diputaciones provinciales que corresponden. Algunas de estas corporaciones han enviado los arreglos de sus secretarías, propuesto varias dudas pertenecientes al orden accidental de la presencia y renovación de sus individuos, cuyos expedientes se irán enviando al Congreso para su resolución (91).

Con anterioridad hay referencias breves y, en ocasiones, indirectas. El 23 de agosto de 1820 se anuncia haberse jurado la Constitución en la isla de Puerto Rico «por su Capitán general, jefe político, ayuntamiento constitucional, diputación provincial y todo el pueblo" (92). El 6 de septiembre, las Cortes quedan enteradas de haberse jurado en Cuba la Constitución «quedando restablecida la diputación provincial y el ayuntamiento constitucional» (93). En la sesión de 18 de marzo de 1822, se lee una «Exposición del ayuntamiento de Puerto Príncipe» dando gracias por el decreto de S.M. de 8 de mayo último relativo al establecimiento de diputaciones en las provincias de Ultramar donde no las hay (94).

En cuanto a los principales centros de poder de la América Española, podemos seguir de una manera más completa la singladura de las diputaciones provinciales. En el caso de Guatemala, las páginas del Editor Constitucional proporcionan información elemental sobre la institución. En ellas puede leerse que se constituyó el 7 de noviembre de 1820 y que funcionó como tal hasta junio de 1824. La diputación provincial se integraría en el proceso de independencia firmando el Acta de proclamación y asesorando

(90) El 29 de septiembre de 1821 se forma la comisión de "División del territorio español" que se ocupa sólo de la Península e islas adyacentes.

(91) Ibídem, I, pág. 130.

(92) Ibidem, I, pág. 613.

(93) Ibidem, pág. 843.

(94) Ibidem, leg. 1822, I, pág. 406. 
al mando supremo en la Junta Provisional consultiva. Su último acto fue la participación en la sesión inaugural del Congreso Constituyente el 24 de junio de 1824 (95).

En Nueva España, una vez jurada la Constitución se procede a la reinstalación de las instituciones liberales. Se conoce bien la trayectoria de las Diputaciones provinciales gracias al trabajo de Nettie Lee Benson. Por él conocemos que en una primera tanda se instalaron seis: Nueva Galicia el 12 de septiembre de 1820; Yucatán (sin precisar); Nueva España (sin precisar); San Luis de Potosí el 17 de noviembre de 1820; las Provincias Internas de Oriente el 20 de noviembre de 1820 y las Provincias Internas de Occidente el 26 de noviembre de 1820. La presión de los representantes novohispanos en las Cortes logró que su número fuera incrementándose progresivamente: a finales de noviembre de 1821 su número era de 18 y en diciembre de 1823 sumaban 23: Chiapas, Chihuahua, Coahuila, Durango, Guadalajara, Guanajuato, México, Mochoacán, Nuevo León, Nuevo México, Nuevo Santander, Oaxaca Puebla, Querétaro, San Luis de Potosí, Sinaloa, Sonora, Tabasco, Texas, Tlaxcala, Veracruz, Yucatán y Zacatecas. Algunas de ellas sobrepasaron sus funciones reglamentarias, asumiendo poderes como gobierno local (96).

Para el caso del Perú, la ausencia de fuentes dificulta la posibilidad de hacer un análisis semejante. Apenas puede establecerse su número y el marco cronológico en que se desarrollaron. Cuando el Secretario de Estado y del Despacho de la Gobernación de Ultramar, señor Ramón Gil de la Cuadra informa de la restauración de la diputación provincial en diversas regiones, reconoce que: «de las provincias del Perú no se tienen más avisos oficiales que los de haberse recibido en la capital de Lima en el mes de julio la noticia agradable de la restauración en la Península del régimen constitucional» (97). Sabemos sin duda que la de Lima se reinstala el 20 de septiembre de 1820 presidiendo el acto el virrey Pezuela. Están presentes Bartolomé María de Salamanca (intendente interino de Lima), Francisco de Moreyra (por Lima), Manuel Bermúdez (por Tarma, Camilo Márquez (por Huancavelica), Nicolás Arancibar por Arequipa y los suplentes Antonio Bedoya y Manuel Cebada. El libro de Actas constata que se celebran sesiones hasta el 12 de abril de 1821. En los últimos días se aprecia la alarma ante la inminente intervención

(95) Ver para esta etapa Sáenz de Santamaría [35], págs. 235-255.

(96) Benson [7], págs. 47-84.

(97) D.S.C. leg. 1821, I, 131. 
de la Expedición Libertadora de San Martín. En el Cuzco, diversos documentos existentes en la Biblioteca Nacional del Perú permiten colegir que se constituye el 27 de enero de 1821 y que funciona hasta su extinción en marzo de 1824 (98). En esta etapa fue una institución claramente fidelista. Y por último una referencia a una diputación prácticamente desconocida, la de Puno que se instala el 16 de junio de 1822 y celebra un total de 102 sesiones hasta el 27 de febrero de 1824 (99). Sobre otras diputaciones provinciales en el Virreinato no contamos con información fiable, las noticias indirectas que proporcionan las de Lima, Cuzco y Puno señalan que la hubo en Arequipa, Charcas, Potosí y Cochabamba.

\subsection{Atribuciones y competencias}

La delimitación de competencias corre pareja a la atención que las Diputaciones provinciales americanas reciben por parte del ejecutivo y de las Cortes. Hasta 1823 continúa vigente la «Instrucción para el Gobierno económico-político de las Provincias de 23 de junio de 1823 en el intervalo se introducen algunas normas innovadoras que afectan a cuestiones concretas.

En la sesión de 10 de octubre de 1820 las Cortes aprueban el Reglamento provisional para la Milicia Nacional en las Provincias de Ultramar, que regula los cuerpos o compañías urbanas de esta clase de aquellas provincias excepto Cuba, Santo Domingo y Puerto Rico, acordando «que se entendiese para con las Milicias de Ultramar lo resuelto respecto de las de la Península, ya relativamente a los empleados públicos, ya facultando a las diputaciones provinciales para resolver las quejas y dudas relativas a la formación y servicios de las expresadas Milicias en sus respectivas provincias» (100).

Las diputaciones provinciales intervienen en su financiación dando su aprobación para que en caso necesario los ayuntamientos usen de los fondos de propios y arbitrios; a través del jefe político pueden hacer propuestas específicas a las Cortes, y en última instancia «quedan autorizadas a resolver sin ulterior recurso las quejas y dudas relativas a la formación y servicio de la Milicia nacional en su respectiva provincia, sin que por esto

(98) BNP. Sala de investigadores Mss. D. 796 y D. 9.556 respectivamente.

(99) Actas de la Diputación Provincial de Puno.

(100) D.S.C. 1820, II, 1.537. 
dejen de ser obedecidas las providencias de la autoridad superior» (101).

A propuesta de las Comisiones de Hacienda y Comercio, las Cortes, en sesión Extraordinaria de 8 de noviembre de 1820 , aprueban que en las provincias de Ultramar las diputaciones provinciales autoricen la entrada con los derechos convenientes de los lienzos ordinarios y aperos de hierro necesarios para la agricultura, si no pueden proveerlos las fábricas nacionales». En cuanto a la cuestión educativa, el Plan de Instrucción Pública se discute durante meses en la Cámara. Las comisiones estudian las adiciones propuestas por los diputados americanos. En junio de 1821 acceden añadir en el artículo 11 que se refiere al establecimiento de escuelas, "o donde o por quienes las Diputaciones provinciales determinen" (en el Decreto definitivo será el artículo 13). El 29 de junio se promulga por fin el Reglamento General de Instrucción Pública que consta de 12 títulos y 130 artículos. La atención a Ultramar es constante, definiéndose minuciosamente el papel de las diputaciones: así en lo relacionado con la enseñanza primaria son las que proponen cómo se impartirá en las poblaciones donde por diversas razones no haya escuela (art. 14); examinan a los que serán lo maestros (art. 15), encargándose además de fijar la renta anual que deben tener como también la cuantía de las jubilaciones y pensiones por imposibilidad, oyendo a los ayuntamientos (art. 18); y en definitiva "las Diputaciones provinciales de toda la Monarquía cuidarán de establecer desde luego, bajo su más estrecha responsabilidad, estas escuelas, dando cuenta al gobierno de haberlo verificado" (art. 20). Se encargan por otra parte de determinar dónde, en qué condiciones y con qué dotación se han de establecer escuelas públicas "en que se enseñe a las niñas a leer, escribir y contar, y a las adultas las labores y habilidades propias de su sexo" (arts. 120-121). Y por último, en cuanto a los fondos destinados a la instrucción pública en general "se autoriza al gobierno para que oyendo a las Diputaciones provinciales y Ayuntamientos respectivos destine a Universidades y escuelas los edificios públicos que elija como más a propósito entre los pertenecientes a establecimientos o corporaciones suprimidas" (art. 128) (102).

(101) Colección de Decretos y Ordenes que han expedido las Cortes generales y Extraordinarias (en adelante C.D.O.) desde su instalación de 24 de septiembre de 1810 hasta el 19 de febrero de 1823, 10 vols. (Madrid, 1820-1823). Decreto XLIX de 14 de octubre de 1820. A pesar de la referencia en el vol. 10 hay decretos de hasta el 3 de marzo de 1823.

(102) C.D.O., Decreto LXXXI de 29 de junio de 1821. 
La injerencia en asuntos relacionados con la libertad de expresión del ciudadano se produce a través de la sufragación de los gastos y sueldos del secretario y demás dependientes de las Juntas protectoras, utilizando para ello los fondos a su disposición, según consta en el Reglamento de las Juntas protectoras de Libertad de Imprenta (103).

Por último, hay que hacer mención especial al protagonismo que cobra la institución en lo relativo al fomento de población y división del territorio. A lo largo del mes de junio se discute en efecto el Proyecto de Ley sobre Fomento de Población y Reparto de Territorios de Ultramar. La ponencia inicia la lectura el día 6 con la intervención del conde de Toreno y Ramos Arizpe. Los artículos en los que aparece la Diputación provincial se van aprobando sin modificaciones, únicamente el diputado por Sevilla, señor Zapata, propone recortar sus prerrogativas en la concesión de territorios para lo cual se resuelve que se ajusten al artículo 13 que obliga a los nuevos pobladores a ocupar y cultivar la tierra en el término de 6 años (104). Estudiadas por la Comisión de Ultramar las diferentes adiciones, el Decreto se promulga el día 27 de junio bajo el título de Ley sobre nuevas poblaciones de Ultramar. Sus 36 artículos incluyen las condiciones en las que, los extranjeros podrán establecerse en las provincias americanas y aquéllas en las que tanto extranjeros como españoles, podrán capitular sobre el establecimiento de poblaciones nuevas. Las Diputaciones provinciales actúan como mediatizadoras, y en este sentido se ocupan de recibir los proyectos de capitulaciones y aprobarlos si se ajustan a las Leyes de Indias (art. 5); designar el suelo en que se han de asentar las nuevas poblaciones, que deberán comprender al menos 20 familias (éste ha de ser baldío, es decir, libre de todo derecho de propiedad o posesión respecto de persona particular o comunidad (art. 7); conceder nuevos territorios cuando los pobladores hayan cultivado y ocupado todos los que ya obtuvieron o cuando por dedicarse a cría de ganado necesitaran más extensión (art. 19) y aprobar los arbitrios con que ha de contribuir toda nueva población a los gastos municipales y de común utilidad (art. 32) (105).

En febrero de 1823 se promulga la Ley para el Gobierno

(103) D.S.C. 1820, III, 2.337. Sesión Extraordinaria de 18 de junio de 1821.

(104) Ibidem,. Leg. mayo-junio de 1821, pág. 2.359. Sesión Extraordinaria de 19 de junio de 1821 .

(105) En Sesión Extraordinaria de 28 de junio el Presidente de las Cortes nombra a la diputación que presentará al Rey el decreto de nuevas poblaciones de Ultramar con carácter de ley y al día siguiente el Presidente de la Comisión, Ramos Arispe, comunica que el monarca se dispone a pasarlo al Consejo de Estado. D.S.C. leg. marzo-junio 1821, págs. 2.584 y 2.809. 
Económico-politico de las Provincias, para la Península e islas adyacentes. Ultramar tendrá que aguardar un mes para que en medio de los problemas ya mencionados que acorralan al sistema constitucional, el 15 de marzo se inicie la discusión del Proyecto de Instrucción para el Gobierno Económico-político de las Provincias. En las intervenciones iniciales, los diputados Bringas y Garmencia hacen notar las circunstancias especiales que atraviesan aquellos territorios: el primero llega a plantear la impugnación del dictamen dado que la actual situación haría impracticable las disposiciones que se aprobaran; Garmendia por su parte apunta que quizás lo más conveniente fuera que se les remitiera el Reglamento sancionado por las Cortes para la Península para que cada una tomara lo que le pareciera más a propósito. Por la comisión defiende el Proyecto el señor Varela, argumentando que se han tenido en cuenta todos los casos y circunstancias y suplica al Congreso que admita la discusión para que aquellas provincias tengan leyes conforme al sistema liberal y no sean gobernadas al arbitrio de jefes militares. En su apoyo, el señor Isturiz aduce que si América es parte integrante de la Monarquía española tiene igual derecho a que se respeten sus peculiaridades. Las Cortes deciden finalmente que el Proyecto se vote en su totalidad. Las discusiones abarcan las sesiones de los días 15, 16, 19, 20 y 21 de marzo. Se interrumpen al disolverse la Cámara y se reanudan en Sevilla a finales de abril, ya consumada la invasión francesa.

En los tres títulos que lo conforman, el Proyecto atiende en profundidad a ayuntamientos, diputaciones provinciales y jefes políticos. Se mantiene, sin resolverse, la interferencia de competencias que ya existía en 1813 quedando como asignatura pendiente la pretendida consecución de una balanza entre poderes. Si nos atenemos concretamente a la institución en estudio, podemos advertir que, en relación con los ayuntamientos interviene en la delimitación del número de casas necesario para que se haga ayuntamiento (art. 1); puede llegar a resolver asuntos que el ayuntamiento ha dejado pendientes después de haberlos tratado en sus sesiones (art. 16); aprueba las contribuciones municipales establecidas por los ayuntamientos (art. 19); recibe anualmente en el mes de octubre los presupuestos de gastos del ayuntamiento para el siguiente año (art. 35); acusa recibo de presupuestos extraordinarios y los aprueba si pasan de 100 pesos fuertes (art. 36); recibe las Ordenanzas municipales y las remite con un informe a las Cortes (art. 40); encarga a los ayuntamientos la formación del censo y estadística de la provincia (art. 43); y, 
en general, cuida de que desempeñen las funciones que están a su cargo (art. 131).

El Título II engloba lo relacionado más específicamente con la diputación. En él se dispone su número y composición en cada provincia, ha de ser de una formada por el jefe político superior, el intendente y siete individuos, más tres suplentes (arts. 80 y 81). Para formar parte de ella, además de los requisitos que exige la Constitución, será necesario que haya residido uno de los siete años en el partido por donde se le nombra o que tenga propiedad cuando no sea de su naturaleza (art. 83), quedan excluidos aquellos que lo están de ser diputados a Cortes. Deberá reunirse el día uno de junio de cada año y celebrar noventa sesiones públicas, según establece la Constitución, distribuidas en las épocas que más convenga, y una sesión secreta cada seis meses a la que no asistirán ni el jefe político ni el intendente, pues en ella se tratará su conducta pública (arts. 84 al· 86).

Entre los artículos 134 y 176 se dirimen las relaciones con el jefe político que continúan siendo ambiguas por los interdependientes. Para comenzar, éste, que es el primer agente delegado del poder ejecutivo, es quien actúa de enlace con las Cortes y el Gobierno, debiendo dar curso sin dilación ni entorpecimiento a los expedientes (art. 152) y cooperando a la ejecución de acuerdos y disposiciones (art. 176); preside con voto la Diputación, pudiendo suspender la ejecución de alguna ley, decreto $u$ orden en circunstancias especiales; aprueba las cuentas de propios y arbitrios con el visto bueno de la diputación (art. 167); cuida de que ésta cumpla con la recogida de la información que le reclame el gobierno (art. 173); y es en definitiva el encargado de ejecutar las órdenes del Rey de suspender las diputaciones que abusen de sus atribuciones (art. 164). Pero, a su vez, la gestión del jefe político se halla supeditada en muchas cuestiones a la intervención de la Diputación. Así, por ejemplo, su sueldo y el del secretario, dependen del informe de las diputaciones (art. 143) que presentan la terna a partir de la cual el jefe selecciona a los miembros de su secretaría (art. 144).

Un seguimiento atento de las funciones específicas de la diputación provincial ratifica cómo en el papel el gobierno económicopolítico de Ultramar se convierte en una tela de araña de difícil salida. Corre a su cargo la elaboración del censo y estadística de sus provincias, con intervención de los ayuntamientos (art. 104); vela por que los presupuestos que le han de remitir los ayuntamientos cumplan la normativa (arts. 106-107); atiende al buen 
funcionamiento de los establecimientos piadosos y de beneficencia (art. 108) y de las milicias locales (art. 114); da los permisos para la venta, permuta o enajenación a censo de las fincas de propios de los pueblos (art. 116); supervisa la reducción a propiedad particular de los terrenos realengos y baldíos (art. 117); procura el establecimiento de posadas en los puntos necesarios, y en general de otras obras de utilidad nacional (arts. 118-119) y elabora expedientes sobre el presupuesto de sus propios gastos ordinarios (arts. 120-123).

Con la lectura del artículo 189, referido a los deberes de los jefes subalternos, se detiene el debate. La última referencia al Proyecto se produce en la sesión de 15 de mayo, cuando la comisión encargada presenta su dictamen acerca de las varias adiciones hechas a diferentes artículos. La comisión es partidaria de su aprobación, únicamente los señores Buey, Prado y Buaruaga ponen en tela de juicio el que los eclesiásticos puedan presidir la Diputación provincial (106).

A punto de disolverse, a comienzos de agosto de 1823, las Cortes reciben a la comisión de Ultramar que, a la vista de la Memoria del Secretario del ramo, propone que se formulen posibles términos de negociación con las "provincias disidentes». "In extremis», el Secretario interino de la Gobernación de Ultramar da a conocer que el gobierno ya ha enviado comisionados para que solucionen lo que al fin y al cabo son puramente «disensiones de familia" (107).

(106) D.S.C. Sesiones celebradas en Sevilla pág. 103.

(107) Ibidem, págs. 402 y 407, sesiones de 2 y 3 de agosto de 1823 respectivamente. 